\title{
Discovering the Protective Effects of Resveratrol on Aflatoxin B1-Induced Toxicity: A Whole Transcriptomic Study in a Bovine Hepatocyte Cell Line
}

\author{
Marianna Pauletto ${ }^{1}\left(\mathbb{D}\right.$, Mery Giantin $^{1}$ (D), Roberta Tolosi ${ }^{1}$, Irene Bassan ${ }^{1}$, Andrea Barbarossa ${ }^{2} \mathbb{D}$, Anna Zaghini $^{2} \mathbb{D}$ \\ and Mauro Dacasto $1, *$ (D) \\ 1 Department of Comparative Biomedicine and Food Science, Division of Pharmacology and Toxicology, \\ University of Padova, Viale dell'Università 16, Legnaro, 35020 Padova, Italy; \\ marianna.pauletto@unipd.it (M.P.); mery.giantin@unipd.it (M.G.); roberta.tolosi@phd.unipd.it (R.T.); \\ irene.bassan@unipd.it (I.B.) \\ 2 Department of Veterinary Medical Sciences, University of Bologna, Via Tolara di Sopra 50, Ozzano \\ dell'Emilia, 40064 Bologna, Italy; andrea.barbarossa@unibo.it (A.B.); anna.zaghini@unibo.it (A.Z.) \\ * Correspondence: mauro.dacasto@unipd.it; Tel.: +39-049-827-2935
}

\section{check for} updates

Citation: Pauletto, M.; Giantin, M.; Tolosi, R.; Bassan, I.; Barbarossa, A.; Zaghini, A.; Dacasto, M. Discovering the Protective Effects of Resveratrol on Aflatoxin B1-Induced Toxicity: A Whole Transcriptomic Study in a Bovine Hepatocyte Cell Line. Antioxidants 2021, 10, 1225. https:// doi.org/10.3390/antiox10081225

Academic Editors: Filomena Nazzaro and Vincenzo De Feo

Received: 5 July 2021

Accepted: 27 July 2021

Published: 29 July 2021

Publisher's Note: MDPI stays neutral with regard to jurisdictional claims in published maps and institutional affiliations.

Copyright: (c) 2021 by the authors. Licensee MDPI, Basel, Switzerland. This article is an open access article distributed under the terms and conditions of the Creative Commons Attribution (CC BY) license (https:// creativecommons.org/licenses/by/ $4.0 /)$.

\begin{abstract}
Aflatoxin B1 (AFB1) is a natural feed and food contaminant classified as a group I carcinogen for humans. In the dairy industry, AFB1 and its derivative, AFM1, are of concern for the related economic losses and their possible presence in milk and dairy food products. Among its toxic effects, AFB1 can cause oxidative stress. Thus, dietary supplementation with natural antioxidants has been considered among the strategies to mitigate AFB1 presence and its toxicity. Here, the protective role of resveratrol $(\mathrm{R})$ has been investigated in a foetal bovine hepatocyte cell line (BFH12) exposed to AFB1, by measuring cytotoxicity, transcriptional changes (RNA sequencing), and targeted posttranscriptional modifications (lipid peroxidation, NQO1 and CYP3A enzymatic activity). Resveratrol reversed the AFB1-dependent cytotoxicity. As for gene expression, when administered alone, $R$ induced neglectable changes in BFH12 cells. Conversely, when comparing AFB1-exposed cells with those co-incubated with R+AFB1, greater transcriptional variations were observed (i.e., 840 DEGs). Functional analyses revealed that several significant genes were involved in lipid biosynthesis, response to external stimulus, drug metabolism, and inflammatory response. As for NQO1 and CYP3A activities and lipid peroxidation, $\mathrm{R}$ significantly reverted variations induced by AFB1, mostly corroborating and/or completing transcriptional data. Outcomes of the present study provide new knowledge about key molecular mechanisms involved in $\mathrm{R}$ antioxidant-mediated protection against AFB1 toxicity.
\end{abstract}

Keywords: aflatoxin B1; aflatoxicosis; mycotoxins; resveratrol; antioxidants; cattle; liver; RNAseq; transcriptome; cancer

\section{Introduction}

Aflatoxins (AFs) are mycotoxins naturally affecting cereal grains and animal feeds around the world [1,2]. They can cause various diseases and health issues in humans and farmed animals. In the latter, AFs exposure might have severe implications, such as liver damage, nutritional or immunological consequences. These effects lead to decreased animal growth and productivity [3-5], ultimately resulting in significant economic losses [6,7]. The most toxic member of this group of mycotoxins is aflatoxin B1 (AFB1), that is also known as the most potent natural hepatocarcinogen [8], thus leading the International Agency for Research on Cancer (IARC) to classify this mycotoxin as a Group I human carcinogen [9].

The great toxicity of AFB1 is based on a bioactivation process. Indeed, AFB1 is biologically activated by a number of cytochromes P450 (CYPs), namely CYP1A and CYP3A, to an extremely reactive and electrophilic derivative, AFB1-8,9-epoxide (AFBO), 
that binds DNA and proteins [10]. Such AFBO-DNA and AFBO-protein adducts inhibit RNA and protein synthesis [3], ultimately leading to severe toxicity and eventually cancer development [8].

Besides AFB1, the most toxic aflatoxin is AFM1. AFB1, following animal intake, can be rapidly hydroxylated to form AFM1, which is efficiently transferred to milk, thus representing a safety concern for humans consuming dairy products [11]. Aflatoxin B1 can be also converted to relatively less-toxic metabolites, such as aflatoxicol (AFL).

Remarkably, species differences in the constitutive expression and catalytic activity of bioactivating and detoxifying enzymes appear crucial in determining the different susceptibility to AFB1 among farmed species [12]. In this respect, the presence of rumen microflora in cattle is a key factor in mitigating AFB1 toxicity, mainly because it converts part of the ingested mycotoxin into less toxic, or nontoxic, metabolites [13]. Nonetheless, in cattle, AFs interfere with the overall ruminal digestive capacity [14], are absorbed at the intestinal level, and are responsible for a plethora of clinical symptoms (e.g., impaired reproductive efficiency, diarrhoea, mastitis) $[15,16]$.

The animal intake of AFs always accompanies the production of Reactive Oxygen Species (ROS) and the resulting oxidative damage [17-19], which may be a major trigger of detrimental outcomes [20]. For this reason, to prevent or mitigate aflatoxicosis in farmed animals, the use of feed additives, consisting of botanical extracts with known antioxidant capacities, is a viable option. For instance, the efficacy of curcumin has been widely tested [21-25]; besides curcumin, several natural polyphenols have also been investigated, providing encouraging results [26-32]. Among them, the use of resveratrol $(R)$ represents a promising strategy.

Resveratrol (trans-3,5,40-trihydroxystilbene) is a polyphenolic phytoalexin naturally found in grapes, red wine, berries, peanut skins, and other plant parts and products. It shows a broad range of pharmacological activities, and in plants it serves as a sort of antitoxin. Being an antioxidant polyphenol, $\mathrm{R}$ also shows numerous beneficial health effects, such as anticancer, anti-ageing, and anti-inflammatory effects [33-38]. Moreover, $\mathrm{R}$ has also been demonstrated to affect lipid metabolism, cell proliferation, differentiation, and apoptosis [39-41]. In farm animals, R-supplemented feed has been already tested with some positive results (e.g., in broilers [32,42,43] and swine [44,45]), thus, suggesting that this approach can be effectively implemented in farming practice. Moreover, recent advances in the extraction of $R$ from grape pomace or Polygonum cuspidatum [46-48] lead us to believe that potential low-cost green processing for the fortification of feed products with this antioxidant might be soon introduced.

The molecular mechanisms triggered by $\mathrm{R}$ have been investigated in farm animal species both in vitro and in vivo. For instance, a whole transcriptome study conducted in bovine skeletal muscle cells has recently demonstrated how $\mathrm{R}$ significantly affects the mRNA expression of genes regulating cholesterol and fatty acid metabolism, cell cycle and proliferation [49]. In the same study, sirtuins (SIRTs), regulatory proteins known to protect from inflammation, suppress cell death and activate antioxidant genes [50-52], appeared to be differentially regulated by $\mathrm{R}$ to a significant extent. Resveratrol supplementation in the washing and fertilisation medium of bull sperm significantly decreased ROS and malondialdehyde (MDA) production, and protected mitochondrial function and acrosomal integrity [53]. In cultured bovine mammary epithelial cells (MAC-T), the nuclear factor erythroid 2-related factor 2 (NRF2), a regulator of antioxidant proteins, is required for the cytoprotective effects of R [54]. In juvenile tilapia fed with an R-supplemented diet the resistance to metabolic dysfunction was improved, and genes associated either with the antioxidant response, e.g., superoxide dismutase (SOD), catalase (CAT), and glutathione peroxidase (GPX), than apoptosis and DNA damage were significantly increased [55]. Maternal dietary $\mathrm{R}$ alleviated weaning-associated intestinal inflammation and diarrhoea in offspring through the involvement of biological pathways such as the "T-cell receptor", "Ras signalling" and "cytokine-cytokine receptor interaction" [56]. In broilers, dietary R 
increased muscle glycogen content and total SOD and GPX activities, while it decreased muscle MDA content and lactate dehydrogenase (LDH) activity [57].

Recently, the potential anti-AFB1 activity of R has been explored in rodents. In alcoholAFB1-induced rat hepatocellular carcinoma, a two-week treatment with R $(100 \mathrm{mg} / \mathrm{kg}$ $\mathrm{bw}$ ) restored the level of key antioxidant enzymes (i.e., SIRT1, CAT, and GPX) toward normal levels $[30,58]$. In mice, R decreased AFB1-induced ROS accumulation, ameliorated adverse hepatic functions by increasing hepatic antioxidant capacity and inhibiting the expression of cleaved-caspase-3 protein [59]. Likewise, in Sprague Dawley rats fed AFB1 $(7.5 \mu \mathrm{g} / 200 \mathrm{~g}), \mathrm{R}$ effectively prevented the AFB1-induced testicular damage and lipid peroxidation [60]. Conversely, in a study conducted in 2010 in rats, curcumin, but not $R$, protected from AFB1-induced liver injury [61].

As far as farm animals are concerned, while the overall benefits of dietary $R$ have been largely investigated, the ability of this polyphenol to prevent or mitigate AFB1 toxicity and the underneath molecular mechanisms have been scarcely studied, except for broilers in vivo [32] and cattle in vitro [26,31]. Studies conducted in cattle assessed the effects of $R$ in mammary epithelial cells exposed to AFB1, but hepatic tissue or liver cells have never been subject of investigation. Therefore, the objective of the present study was to investigate the protective role of R against AFB1-induced toxicity in the bovine foetal hepatocyte-derived cell line (BFH12). Moreover, we aimed to elucidate the whole transcriptional changes (RNA-seq) triggered by this natural polyphenol when administered in combination with AFB1. To reach such a goal, cells were at first pre-treated for $16 \mathrm{~h}$ with $\mathrm{R}$; then, monolayers were exposed to $3.6 \mu \mathrm{M}$ AFB1 for further $48 \mathrm{~h}$ in combination with $\mathrm{R}$. As a control, cells exposed only to $\mathrm{R}$ were also included in the experiment.

To date, the impact of R on AFB1-mediated whole transcriptional changes in an established hepatic cell line isolated from veterinary species has never been investigated. This study will help in developing R-supplemented diets to mitigate toxicity induced by AFB1 in dairy cattle. Such feeding improvements might contribute to reduce the risk of dairy products contamination, ultimately preventing significant economic losses.

\section{Materials and Methods}

\subsection{Cell Culture and Chemicals}

The bovine SV40 large T-antigen-transduced foetal hepatocyte-derived cell line BFH12 [62] was cultured using the experimental procedures detailed in our previously published paper [63]. Resveratrol ( $\geq 99 \%$ purity) was obtained from Sigma-Aldrich (St. Louis, MO, USA). All chemicals used in the study are commercially available and of molecular biology grade (see details in [63]). The chemical structure of all the key molecules targeted in the present study (i.e., R, AFB1, AFM1, AFL) has been provided in Figure S1.

\subsection{Resveratrol Cytotoxicity}

Experimental conditions for the cytotoxicity test were those reported in our previous study [21]. Briefly, four days after seeding, cells were exposed to increasing concentrations of $R$ for a total of $64 \mathrm{~h}(16+48 \mathrm{~h}$; range $5-250 \mu \mathrm{M})$. Then, we assessed the ability of $\mathrm{R}(10$, 20 , or $30 \mu \mathrm{M}$ ) to mitigate AFB1-induced cells mortality. In accordance with the approach we followed in our previous studies [21,63], BFH12 cells were pre-treated with an aryl hydrocarbon receptor (AHR) agonist, i.e., PCB126. The rationale of this choice lays on the hypothesis that metabolic competence of foetal hepatocytes may be lower compared to that of adult liver cells. Thus, PCB126 pre-treatment was intended to increase the cell responsiveness to AFB1.

Resveratrol concentrations were chosen based on the half maximal inhibitory concentration $\left(\mathrm{IC}_{50}\right)$ obtained in the present study: the selected concentrations were always below the corresponding $\mathrm{IC}_{50}$. 


\subsection{Cells Incubation for Gene Expression Analysis}

To assess the effects of R treatment upon AFB1-induced transcriptional changes, four independent cell culture experiments were conducted. Details about the experimental procedures (i.e., cells incubation, RNA isolation, RNA concentration and quality assessment) are available in our previously published manuscripts [21,63].

As far as the RNA quality, all samples had an RNA Integrity Number (RIN) value $>7$.

\subsection{Quantitative Real-Time PCR}

A targeted qPCR approach was preliminarily performed to assess the effects of $\mathrm{R}$ at the selected sub-cytotoxic concentrations (i.e., 10, 20, and $30 \mu \mathrm{M}$ ). Only transcripts known to be regulated by AFB1 (i.e., genes involved in AFB1 metabolism and antioxidant response) were considered.

The target gene expression analysis was carried out on four biological replicates (i.e., independent cell culture experiments). A total of four experimental conditions were assessed: CTRL, R (10, 20, and $30 \mu \mathrm{M})$, AFB1, R (10, 20, and $30 \mu \mathrm{M})+$ AFB1. Reverse transcription, qPCR amplification conditions, target genes, primers, and qPCR data analysis were described elsewhere [63].

\subsection{RNA-Seq Library Preparation and Sequencing}

Based on the preliminary qPCR results, besides CTRL and AFB1 experimental conditions, only cells exposed to the maximum concentration of $\mathrm{R}$ (i.e., $30 \mu \mathrm{M}$ ), either alone $(\mathrm{R})$ or in combination with AFB1 (R+AFB1), were subjected to deep transcriptome investigations.

For each experimental condition, three independent biological replicates (i.e., independent cell culture experiments) were assessed. A total of 12 tagged RNA-seq libraries were prepared and sequenced following a $50 \mathrm{bp}$ single-end strategy in an Illumina Hi-Seq 4000 instrument (Fasteris SA, Geneva, Switzerland). Libraries were prepared as previously reported [63]. Briefly, we used the Agilent's SureSelect Strand Specific RNA Library Preparation Kit (Agilent Technologies, Santa Clara, CA, USA) following the manufacturer's instruction. Poly(A) mRNA was purified starting from $400 \mathrm{ng}$ of total RNA and chemically fragmented. First-strand and second-strand cDNA were synthetized and end-repaired. Then, cDNA $3^{\prime}$ ends were adenylated and adaptors were ligated. Twelve cycles of PCR were used to amplify the adaptor-ligated cDNA library. The PCR products were then purified and size-selected using the SPRIselect reagent kit (Beckman Coulter, Brea, CA, USA). Library concentrations were measured adopting two approaches: Qubit RNA Assay kit (Life Technologies, Carlsbad, CA, USA), in a Qubit 2.0 Fluorometer (Life Technologies); PCR-based method using the NEBNext Library Quant Kit for Illumina (New England Biolabs, Ipswich, MA, USA). Individual libraries were monitored for insert size using the Agilent DNA 1000 assay kit (Agilent Technologies) on the Agilent Bioanalyzer 2100 instrument (Agilent Technologies).

Notably, libraries representing CTRL and AFB1 conditions have been previously analysed in a stand-alone study assessing the whole transcriptional effects of PCB126 and AFB1 on BFH12 cells [63]. In the present study, these libraries have been normalized and analysed again in the context of a larger dataset including new data (i.e., cells treated with $\mathrm{R}$ and $\mathrm{R}+\mathrm{AFB} 1$ ).

\subsection{Differential Expression Analysis}

Differential expression (DE) analysis has been conducted as previously described in [21] with minor modifications. Analysis of differential gene expression was conducted using EdgeR [64] and grouping samples according to treatment (i.e., CTRL, R, AFB1, $\mathrm{R}+\mathrm{AFB} 1$ ). Pair-wise analysis were performed to assess the transcriptional changes induced by $R$ alone (i.e., $R$ vs. CTRL) and $R$ in combination with AFB1 (i.e., $R+A F B 1$ vs. AFB1). Common and tag-wise dispersions were estimated (estimateDisp), a linear model was fitted $(g l m Q L F i t)$, and the differential expressed genes (DEGs) were determined ( $g l m Q L F T e s t)$ by 
setting the following thresholds of significance: FDR $\leq 0.05$ and Fold Change (FC) $\geq 1.5$ (i.e., $\log _{2} \mathrm{FC} \geq 0.6$ ). The complete $\mathrm{R}$ code used for the $\mathrm{DE}$ analysis is reported in File $\mathrm{S} 1$.

\subsection{Functional Enrichment Analysis}

A functional interpretation of significant DEGs was obtained through GO (Gene Ontology) and KEGG (Kyoto Encyclopedia of Genes and Genomes) over-representation tests implemented in R environment, and using functions included in the ClusterProfiler package (i.e., enrichGO, enrichKEGG) [65]. Ensembl gene identifiers were used to establish two different gene lists (i.e., significantly up- and downregulated genes) and a "background" (i.e., all expressed genes). Dotplots and gene-concept networks were also constructed by using specific functions available in the ClusterProfiler package. Gene Ontology terms redundancy was removed by using the simplify function (similarity cutoff $=0.5$ ). Dotplots display the most significant enriched terms $(p$-value $\leq 0.05)$, while gene-concept networks highlight which genes were involved in the significant GO terms.

A pre-ranked KEGG Gene Set Enrichment Analysis (GSEA) [66] was also performed. This statistical approach is helpful to determine whether gene sets defined a priori show statistically significant enrichment at either end of the ranking. A statistically significant enrichment value (Benjamini-Hochberg adjusted $p$-value $\leq 0.05$ ) indicates that the biological activity (e.g., the biomolecular pathway), characterized by the gene set, is correlated with the supplied ranking. The ranked input was prepared as specified in [21]. The analysis was carried out by using the gseKEGG function provided by the ClusterProfiler package [65].

The detailed $\mathrm{R}$ codes used for the bioinformatic analysis are reported in File S1.

\subsection{Analytical Investigations}

At the end of the experiment, medium and cell samples were collected and total AFB1, AFM1, and AFL were measured by LC-MS/MS in all experimental conditions, following the procedure detailed in [63].

\subsection{Oxidative Stress}

Pro-oxidant effects of AFB1 and the potential benefits of $\mathrm{R}$ were assessed by measuring lipid peroxidation (MDA production) in the same experimental groups assessed by RNAseq. Notably, lipid peroxidation is one of the main manifestations of oxidative damage and it is known to play an important role in AFB1 toxicity. The detailed protocol is provided in [21].

\subsection{NQO1 and CYP3A Enzymatic Activity}

The catalytic activity of two key enzymes involved in the antioxidant response and in AFB1 bioactivation, i.e., $\mathrm{NQO1}(\mathrm{NAD}(\mathrm{H})$ :quinone oxidoreductase 1) and CYP3A, were investigated, as they were here reported to be transcriptionally modulated by treatments. Enzymatic activities were measured in the same experimental groups considered for RNAseq analysis.

Diaphorase, or NQO1, was selected as it is a multifunctional and stress-inducible protein involved in antioxidant defence and detoxification processes. It reduces quinone to hydroquinone, thus avoiding the formation of semiquinones and species with reactive oxygen radicals that are deleterious to cells [67]. The diaphorase activity was assessed using an Abcam commercial kit (ab184867 NQO1 activity assay kit), following the manufacturer's instructions.

The cytochrome P450 3A was selected as it plays a pivotal role in the bioactivation of AFB1 and in the formation of the highly reactive epoxide intermediate AFB(1)-8,9epoxide [8]. Catalytic activity of CYP3A was measured using a Promega commercial kit (P450-Glo ${ }^{\mathrm{TM}}$ CYP3A4 assay with Luciferin-IPA), following the protocol detailed in [21]. Six independent cell culture experiments were performed in sextuplicate. Catalytic activity results were expressed as normalized to the number of living cells; to this purpose, CellTiter- 
Glo $^{\mathrm{TM}}$ cell viability assay kit (Promega), assaying ATP as a marker for basal metabolic activity, was used.

\subsection{Statistical Analysis}

Dose-response curves, box and whiskers plots, bar plots and related statistical analysis were obtained by using GraphPad Prism software (version 8.0.2, San Diego, CA, USA).

\section{Results}

\subsection{Resveratrol Cytotoxicity}

Cells were exposed for $16+48 \mathrm{~h}$ to increasing $\mathrm{R}$ concentrations, and dose/response curves were built to define the corresponding $\mathrm{IC}_{50}$ values. After $64 \mathrm{~h}$ of incubation, the $\mathrm{IC}_{50}$ value was $56.06 \mu \mathrm{M}\left(\mathrm{R}^{2}=0.97\right)$ (Figure $\left.1 \mathrm{a}\right)$.

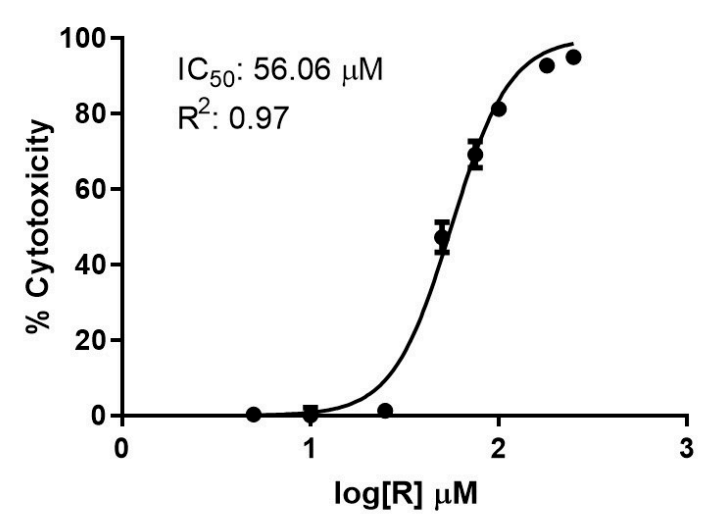

(a)

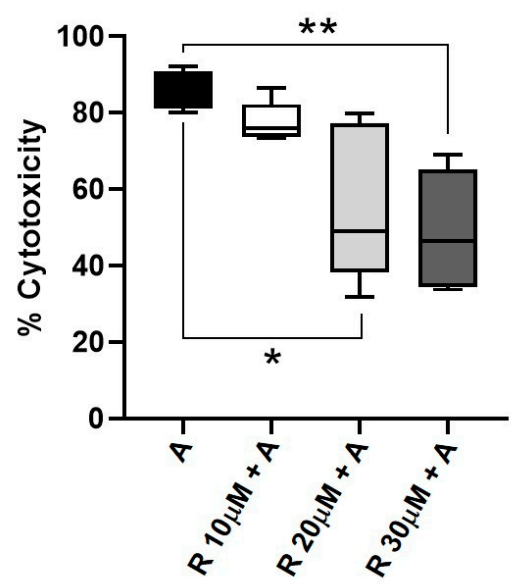

(b)

Figure 1. Cytotoxicity. (a) Resveratrol dose-response curve in BFH12 cells (64 h), based on three independent cell culture experiments, each one run in sextuplicate. Data are expressed in mean cytotoxicity rate \pm standard error of the mean (SEM). $\mathrm{IC}_{50}$ and $\mathrm{R}^{2}$ are also reported. (b) AFB1 cytotoxicity in presence of $\mathrm{R}(16+48 \mathrm{~h})$. The box and whiskers plots report the viability of BFH12 cells pre-treated with $\mathrm{R}$ increasing concentrations $(10,20$, and $30 \mu \mathrm{M})$ and exposed for $48 \mathrm{~h}$ to a combination of AFB1 $3.6 \mu \mathrm{M}$ and R (same concentration reported above). ${ }^{* *} p \leq 0.01,{ }^{*} p \leq 0.05$ (Kruskal-Wallis and Dunn's multicomparisons tests; the mean of each condition was compared with the mean of the AFB1 condition). Graphs were obtained by means of GraphPad prism software. $\mathrm{R}=$ resveratrol; $\mathrm{A}=\mathrm{AFB} 1$.

The cytotoxicity assessed following the AFB1 and R co-treatment showed that $\mathrm{R}$ mitigated AFB1-induced cytotoxicity in a dose-dependent manner. In particular, the highest $R$ dose (i.e., $30 \mu \mathrm{M}$ ) significantly reduced the median AFB1 cytotoxicity, dropping from $86.00 \%$ to $49.22 \%$ (Figure 1 b).

\subsection{Aflatoxin B1 Biotransformation in BFH12 Cells}

Bovine foetal hepatocytes metabolized AFB1, producing and releasing into the medium its foremost derivatives, i.e., AFM1 and AFL (Figure S2). Resveratrol significantly decreased the amount of AFM1 in a dose-dependent manner, reducing this metabolite from $57.00 \mathrm{ng} / \mathrm{mL}$ (i.e., $0.174 \mu \mathrm{M}$ ) to $16.25 \mathrm{ng} / \mathrm{mL}$ (i.e., $0.050 \mu \mathrm{M}$ ). On the contrary, R increased the production of AFL, which reached the highest amount (i.e., $169.50 \mathrm{ng} / \mathrm{mL}$, or $0.539 \mu \mathrm{M}$ ) in the medium of cells co-treated with R $30 \mu \mathrm{M}$ and AFB1. A comprehensive picture of biotransformation processes occurring in BFH12 exposed to AFB1, alone or in combination with $R$, is provided in Figure 2. Beside summarizing the impact of R on AFM1 and AFL formation, Figure 2 also highlights a decrease in AFB1 concentration in presence of R, yet the variations are above the threshold of significance. 


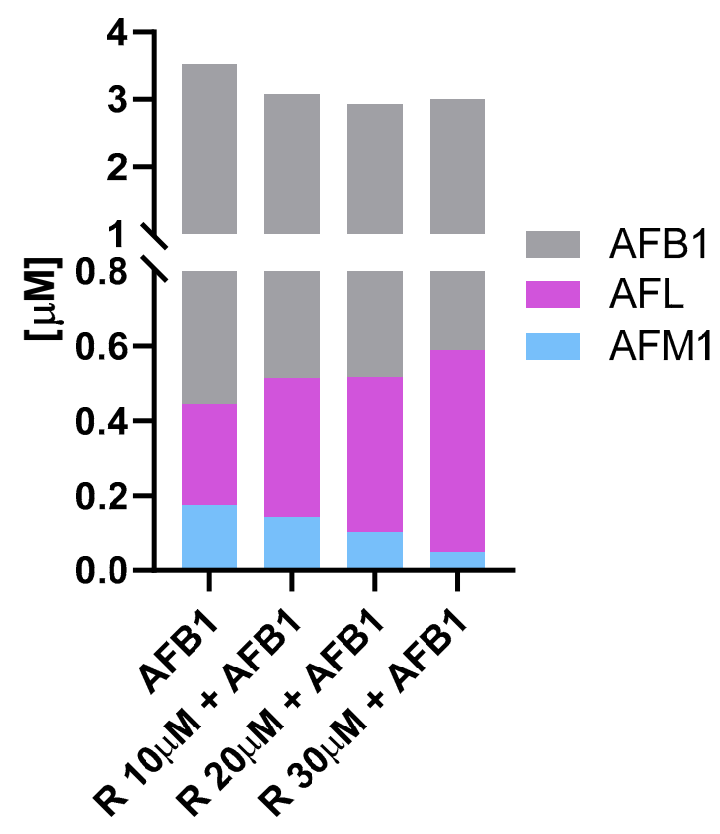

Figure 2. AFB1 biotransformation. The cumulative bar chart reports the micromolar $(\mu \mathrm{M})$ amount of AFB1, AFM1, and AFL detected in the medium of BFH12 cells exposed to AFB1 alone or in combination with 10,20 , or $30 \mu \mathrm{M}$ of $\mathrm{R} . \mathrm{R}=$ resveratrol.3.3. Target gene expression analysis.

In cellular pellets, AFM1 and AFL were not detected, while the amount of cellular AFB1 was generally low in all different experimental conditions (approximately $12 \mathrm{ng} / \mathrm{mL}$, or $0.038 \mu \mathrm{M})$.

\subsection{Target Gene Expression Analysis}

Some key genes involved in phase I and II biotransformation, AHR pathways, and antioxidant mechanisms were affected by R alone or co-administered with AFB1 (Figure S3). The observed patterns of gene expression demonstrated that $\mathrm{R}$ effects are dose-dependent, and the highest dose (i.e., $30 \mu \mathrm{M}$ ) produced maximal variations. The mRNA levels of CYP1A1, CYP3A28 (the orthologue of human CYP3A4, as demonstrated in [68]), and GSTA1 were slightly induced by R. Moreover, in cells incubated with R and AFB1, CYP1A1 and the aryl hydrocarbon receptor repressor (AHRR) were significantly up- and downregulated, respectively.

To obtain net transcriptional results, the RNA-seq studies have been carried out only in cells treated with the highest $R$ concentration.

\subsection{Whole-Transcriptome Differential Expression Analysis}

A total of 291,836,355 raw reads were sequenced and deposited in GeneBank under the BioProject accession PRJNA627332.

Raw reads of all samples passed quality control measures. After trimming and rRNAs removal, approximately 24 million reads per sample were retained. About $99 \%$ of the reads obtained from each RNA-seq library mapped to the B. taurus reference genome. In Table S1 we reported the number of raw reads passing the filters and the number of filtered reads mapping to the cow genome. The MDS plot provided in Figure S4 shows an unsupervised clustering of the samples. The first dimension ( $\mathrm{x}$ axis) clearly separates cells treated with AFB1 (alone or in combination) from those which did not receive AFB1. Transcriptional profiles observed in control cells and those exposed to $\mathrm{R}$ appear very similar, thus forming a unique cluster in the plot. Biological variability within CTRL, AFB1, and R experimental groups is narrow as demonstrated by the coherent clusters formed by replicas. Finally, circles representing the whole transcriptional pattern of cells co-treated with R and AFB1 are more dispersed in the Cartesian plane, thus indicating a certain biological variability between replicas. 
In cells incubated with $\mathrm{R}$ alone, a total of 5 DEGs were found; compared to controls, 4 genes were overexpressed, while only one gene was downregulated. The EdgeR output of the DE analysis conducted in this study was reported in Table S2. Four out of 5 DEGs were involved in inflammatory processes: fatty acid desaturase 1 (FADS1; $\log \mathrm{FC}=0.80)$, high mobility group AT-hook 1 (HMGA1; $\log F C=1.01)$, secreted phosphoprotein 1 (SPP1; $\log F C=2.03)$, and signal peptide, CUB domain and EGF-like domain containing 1 (SCUBE1; $\log F C=-3.20)$.

Gene expression profiles of cells co-treated with R and AFB1 were compared to those of cells treated with AFB1 alone. In BFH12 cells co-treated with R and AFB1, a total of 840 DEGs were identified. The majority of significant genes, i.e., 647, were upregulated, while 193 were downregulated. The EdgeR output of the DE analysis conducted in this study is reported in Table S2. The top-10 up- and downregulated genes are reported in a heatmap (Figure 3). Noteworthy, among the top-10 upregulated genes we found cancerrelated genes such as FosB proto-oncogene (FOSB; $\log \mathrm{FC}=1.89$ ), mesothelin (MSLN; $\log F C=3.06)$, and arrestin beta 1 (ARRB1; $\log F C=1.89)$. The most significant upregulated gene was laminin subunit gamma 2 (LAMC2; $\log F C=1.69$ ), a component of the ECMreceptor interaction pathway. Worth of note, an autophagy-activating kinase (ULK2; $\log \mathrm{FC}=0.87)$ was also found.

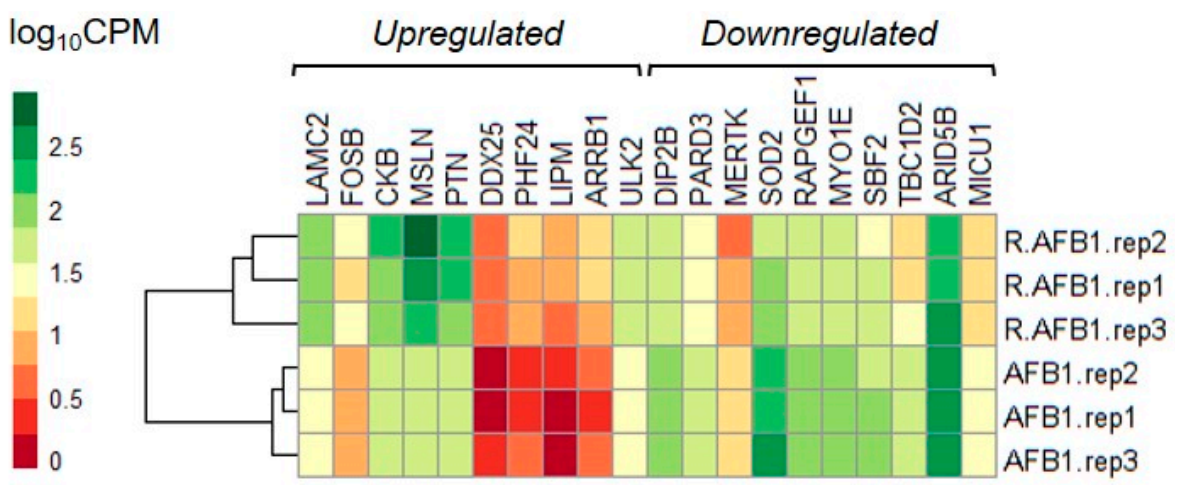

Figure 3. Heatmap of top-10 up- and downregulated genes by R+AFB1 co-treatment (vs. AFB1). The graph was constructed in $\mathrm{R}$ environment using the pheatmap package and using as input the normalized $\log _{10} \mathrm{CPM}$ (Counts Per Million). $\mathrm{R}$ = resveratrol; $\mathrm{A}=\mathrm{AFB} 1$.

Among the top-10 downregulated genes, superoxide dismutase $2(\mathrm{SOD} 2 ; \operatorname{logFC}=-1.30)$ showed the highest fold change. A further gene involved in regulating oxidative stress and inhibited in R + AFB1 co-treated cells was mitochondrial calcium uptake 1 (MICU1; $\log \mathrm{FC}=-0.97)$. Besides, genes with a role in apoptosis were also found, i.e., MER protooncogene, tyrosine kinase (MERTK; $\log F C=-1.30$ ), Rap guanine nucleotide exchange factor 1 (RAPGEF1; $\log \mathrm{FC}=-0.74)$.

The enrichment analysis, carried out on the complete list of DEGs (both up- and downregulated), resulted in 17 significant Biological Processes (BPs) and 7 KEGG pathways (Figure 4, Table S3). Besides the very general terms "system process" (GO:0003008; 35 genes) and "chemical homeostasis" (GO:0048878; 28 genes), a significant BP was "lipid biosynthetic process" (GO:0008610; 27 genes). As regards this term, genes coding for key enzymes in cholesterol formation like 3-hydroxy-3-methylglutaryl-CoA reductase (HMGCR; $\log F C=0.78)$, lanosterol synthase (LS; $\log F C=1.44)$, and $N A D(P)$ dependent steroid dehydrogenase-like (NSDHL; $\log F C=1.07$ ) were upregulated. Several DEGs representing this term play a role in inflammatory processes. This is the case of fatty acid binding protein 5 (FABP5; $\log F C=1.14$ ), apolipoprotein A1 (APOA1; $\log F C=2.17$ ), low density lipoprotein receptor $(L D L R ; \log F C=0.99)$, prostaglandin I2 synthase (PTGIS; $\log F C=1.73)$, phospholipase A2 group IVA (PLA2G4A; $\log F C=-1.14$ ), transmembrane 7 superfamily member 2 (TM7SF2; $\log F C=-1.00$ ), and nuclear receptor subfamily 1 group D member 1 (NR1D1; $\operatorname{logFC}=-0.87$ ). While $\mathrm{R}$ administered alone induced FADS1, the co-treatment with AFB1 
upregulated the expression of both FADS1 $(\log F C=0.74)$ and FADS2 $(\operatorname{logFC}=1.33)$, an analogue to FADS1 but desaturating fatty acid chain at specific positions.

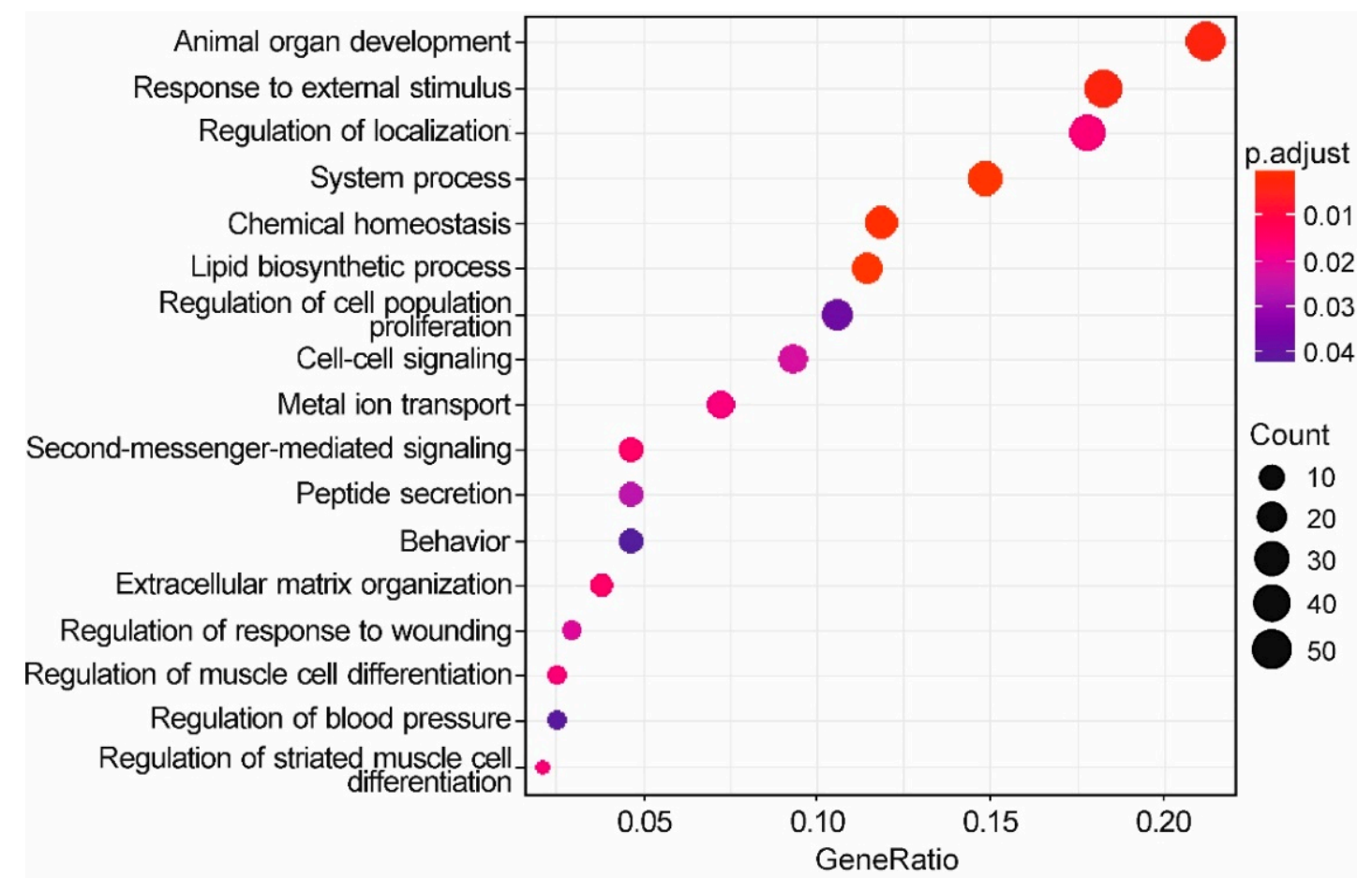

(a)

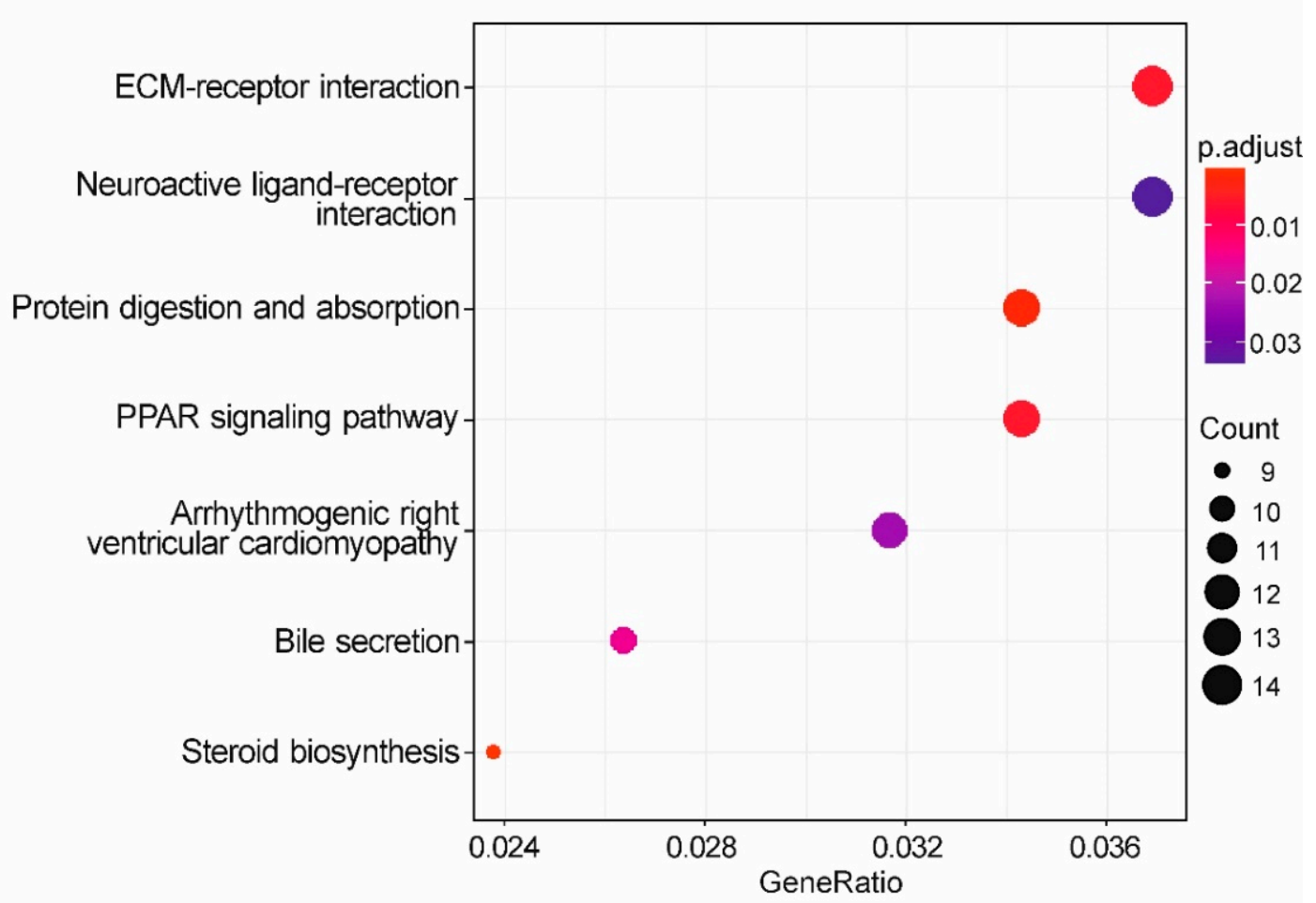

(b)

Figure 4. Functional enrichment of genes regulated by R+AFB1 co-treatment (vs. AFB1). Dot plots representing enriched BPs (a) and KEGG pathways (b). Dot size reflects the number of DEGs in each enriched term. The colour gradient reflects the significance level of each term. $p$-values were adjusted using the Benjamini-Hochberg method. 
Notably, a significantly enriched BP was also the "response to external stimulus" (GO:0009605; 43 genes) with genes like aquaporin 1 (AQP1; $\operatorname{logFC}=2.02$ ), fos protooncogene, AP-1 transcription factor subunit (FOS; $\log F C=1.06$ ), nuclear receptor subfamily 1 group $\mathrm{H}$ member $4(\mathrm{NR} 1 \mathrm{H} 4 ; \log \mathrm{FC}=3.32)$, serpin family $\mathrm{G}$ member 1 (SERPING1; $\log \mathrm{FC}=1.87)$, and fibronectin type III domain containing $4(\mathrm{FNDC} 4 ; \log \mathrm{FC}=1.27)$. All these genes are known to be involved in anti-inflammatory processes. Furthermore, the expression of some pro-inflammatory cytokines like C-X-C motif chemokine ligand 9 (CXCL9; $\log F C=2.79)$, CXCL10 $(\operatorname{logFC}=3.11)$, CXCL11 $(\log F C=2.20)$, and CXCL16 $(\log F C=0.64)$ was significantly induced. As for downregulated genes, some of them have a pro-carcinogenic activity, like the activated leukocyte cell adhesion molecule (ALCAM; $\log F C=-0.61)$, and semaphorin 3C (SEMA3C; $\log F C=-1.24)$. The OMA1 zinc metallopeptidase (OMA1; $\log F C=-0.97)$ is involved in apoptosis, and DNA damage inducible transcript 3 (DDIT3; $\log \mathrm{FC}=-0.69$ ) in cell stress and DNA damage.

Differentially expressed genes playing a role in processes involving cell-cell communication were particularly represented, resulting in the significant enrichment of the BP "extracellular matrix organization" (GO:0030198; 9 genes), "second-messenger-mediated signalling" (GO:0019932; 11 genes), and "cell-cell signalling" (GO:0007267; 22 genes).

As far as KEGG enrichment, the significance of "steroid biosynthesis" (bta00100; 9 genes) is consistent with the enriched BP "lipid biosynthetic process" (see above). Among significant KEGGs, "PPAR signalling pathway" (bta03320; 13 genes) appears particularly interesting.

The GSEA conducted on the output of the DE analysis resulted in 35 significant KEGG pathways (Figure 5, Table S4). Among them, 20 were positively enriched (Normalized Enrichment Score $>0$ ), meaning that a relevant number of genes belonging to these terms were upregulated in $\mathrm{R}+\mathrm{AFB} 1$ compared to AFB1. The remaining 15 pathways were negatively enriched (Normalized Enrichment Score $<0$ ), meaning that a relevant number of genes belonging to these terms were downregulated in R+AFB1 compared to AFB1. Firstly, some positively enriched KEGG pathways, like "ECM-receptor interaction" (bta04512; 58 genes), "steroid biosynthesis" (bta00100; 17 genes), "metabolism of xenobiotics by cytochrome P450" (bta00980; 31 genes), and "axon guidance" (bta04360; 151 genes) confirmed some of the results of the over-representation test (see below). Secondly, the positive enrichment of "glycosaminoglycan degradation" (bta00531; 17 genes) and "lysosome" (bta04142; 114 genes) demonstrated an increased activity of these organelles and their peculiar biochemical reactions, such as the catabolism of glycosaminoglycans (GAGs), structural constituents of the proteoglycans. Furthermore, in the present study the pathway "proteoglycans in cancer" (bta05205; 169 genes) was activated by R and AFB1 co-treatment. Fatty acids metabolism was also impacted by $\mathrm{R}$, as demonstrated by the positive enrichment of "biosynthesis of unsaturated fatty acids" pathway (bta01040; 26 genes). Interestingly, the KEGG pathway "ferroptosis" (bta04216; 35 genes) was significantly activated. Ferroptosis is a type of regulated oxidative cell death that is induced by the accumulation of iron-mediated lipid peroxidation. 


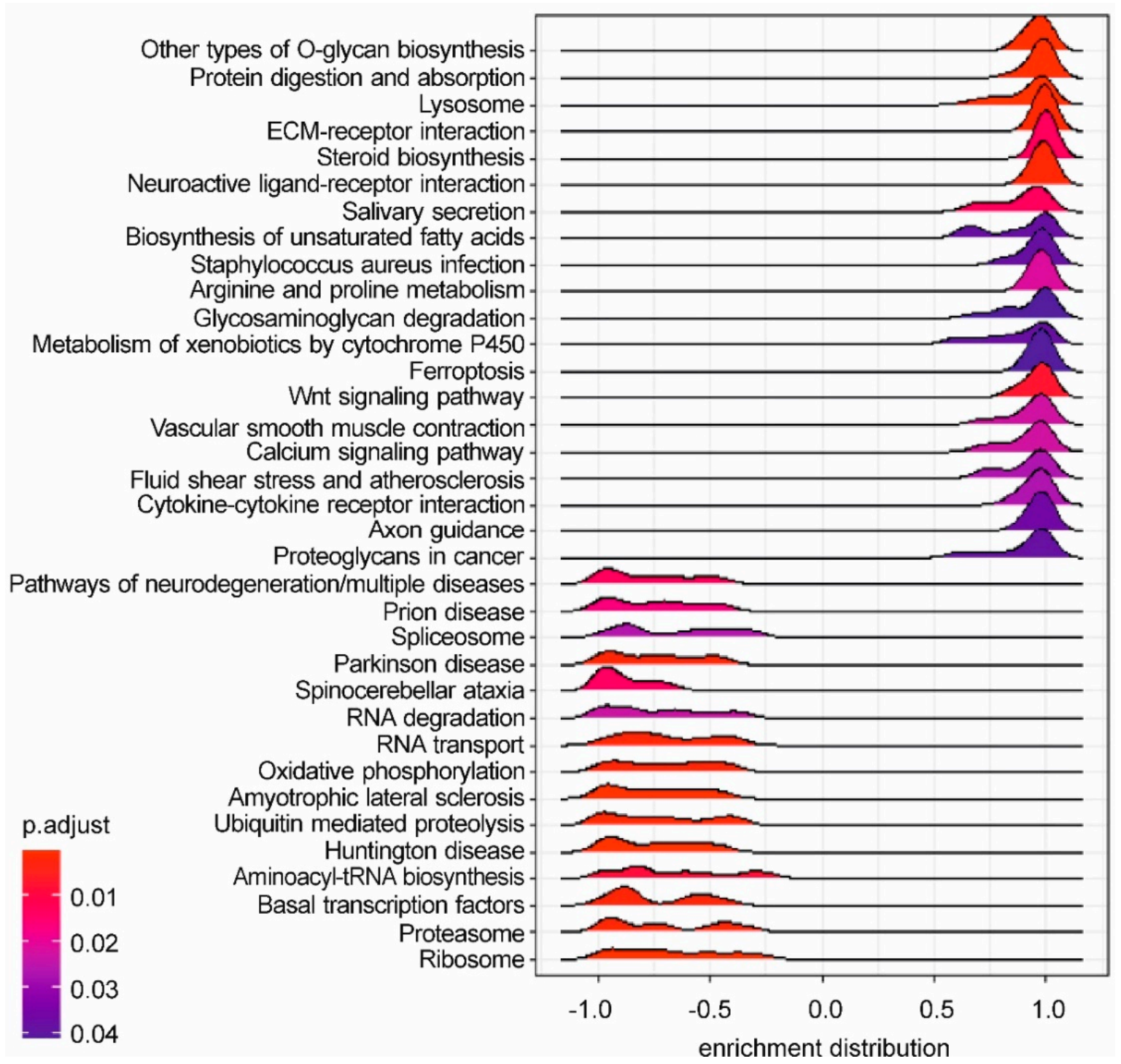

Figure 5. Gene Set Enrichment Analysis: R+AFB1 vs. AFB1. The ridgeplot visualizes the expression distributions of core enriched genes for GSEA enriched KEGG pathways. Gradient colour reflects the adjusted $p$-values (BenjaminiHochberg method).

Among the downregulated gene sets, we found some terms related to RNA processing, like "spliceosome" (bta03040; 124 genes), "RNA degradation" (bta03018; 73 genes), "RNA transport" (bta03013, 150 genes), and "aminoacyl-tRNA biosynthesis" (bta00970; 43 genes). Processes related to protein synthesis and degradation were also suppressed, as demonstrated by the negatively enriched KEGG pathways like "ubiquitin mediated proteolysis" (bta04120; 133 genes), "proteasome" (bta03050; 43 genes), and "ribosome" (bta03010; 128 genes).

\subsection{Oxidative Stress}

In cells, oxidative stress may result in lipid peroxidation. To confirm the pro-oxidant effects of AFB1 and the potential benefits of R we measured the amount of MDA, which is a marker of lipid peroxidation. The amount of MDA significantly increased in BFH12 cells exposed to AFB1 compared to control conditions (Figure 6). The co-incubation with $\mathrm{R}$ significantly reduced the MDA content (Figure 6), thus demonstrating the potential of this natural extract in mitigating AFB1-induced oxidative damage. 


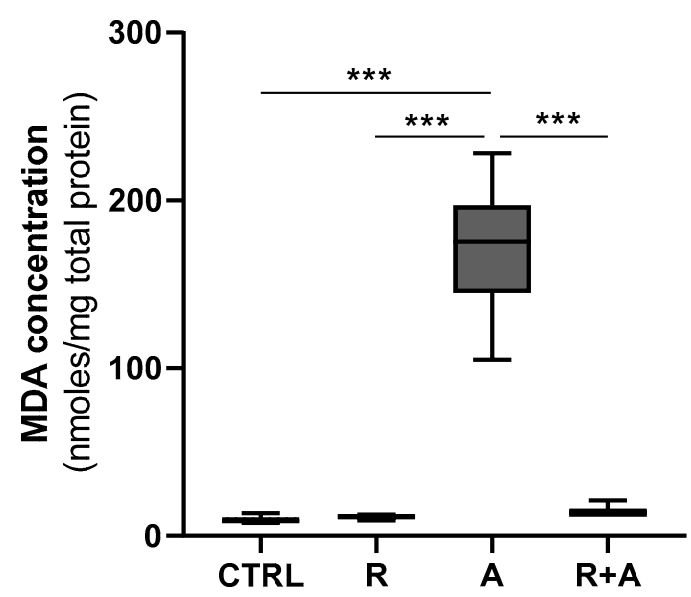

Figure 6. Lipid peroxidation. Box and whiskers plot reports the MDA content in the four different experimental conditions. The statistical comparisons were established between the median MDA concentration in cells exposed to AFB1 and the median MDA concentration observed in all other experimental conditions. Data are expressed as median concentration and data distribution (i.e., quartiles). For each experimental condition, six independent cell culture experiments were performed. CTRL condition corresponds to cells exposed to PCB126 only. $\mathrm{R}=$ resveratrol; $\mathrm{A}=\mathrm{AFB1} .{ }^{* * *} p<0.001$ (one-way ANOVA, followed by Dunnett's multi-comparisons test).

\subsection{Diaphorase Enzymatic Activity}

The activity of NQO1 was selected as a marker of the cell antioxidant status and, additionally, to confirm the trend observed for this specific target at the mRNA level (qPCR and RNA-seq: Figure S3, Table S2). Moreover, this assay was chosen to allow a comparison with findings of our previous study in which we assessed the effects of another antioxidant in BFH12 cells, i.e., curcumin [21].

Aflatoxin B1 reduced the antioxidant activity of NQO1 when compared to CTRL, (Figure 7), though the variation was close but not statistically significant $(p=0.067)$. However, $\mathrm{R}$ alone or in combination with AFB1 significantly induced the NQO1 enzymatic activity, bringing it above that of CTRL cells (Figure 7). This result further corroborates evidence of the antioxidant properties of $R$.

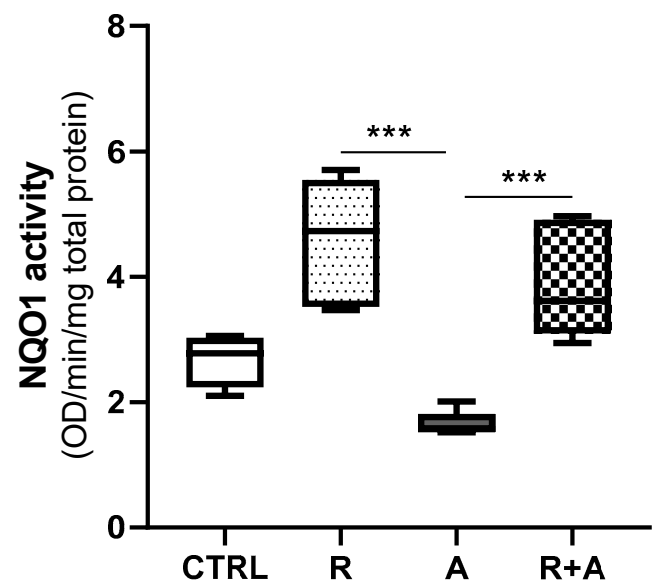

Figure 7. NQO1 enzyme activity. Box and whiskers plot reports the diaphorase activity in different experimental conditions. The statistical comparisons were established between the median NQO1 activity in cells exposed to AFB1 and the median NQO1 activity observed in the other experimental conditions. For each experimental condition, six independent cell culture experiments were performed. Data are expressed as median optical density (OD) observed per min per mg of total protein. CTRL condition corresponds to cells exposed to PCB126 only. $\mathrm{R}=$ resveratrol; $\mathrm{A}=$ AFB1. ${ }^{* * *} p<0.001$ (one-way ANOVA, followed by Dunnett's multi-comparisons test). 


\subsection{Cytochrome P4503A Catalytic Activity}

Cells exposed to AFB1 showed a statistically significant increase in CYP3A activity compared to basal conditions $(p<0.001$, Figure 8$)$. Conversely, the combined exposure to AFB1 and R considerably reduced the CYP3A activity, bringing it back to CTRL levels (Figure 8).

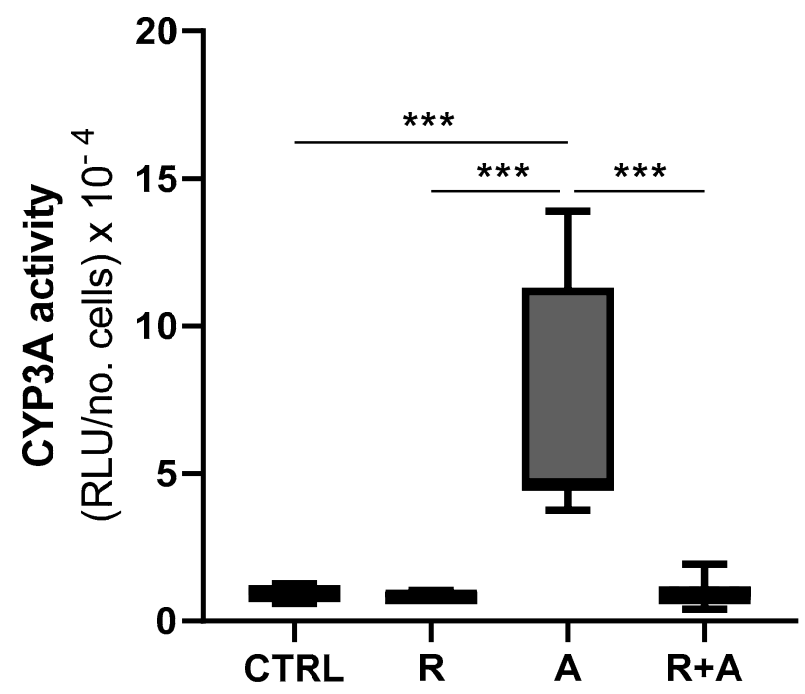

Figure 8. CYP3A enzyme activity. Box and whiskers plot reports the CYP3A activity in different experimental conditions. The statistical comparisons were established between the median CYP3A activity in cells exposed to AFB1 and the CYP3A activity observed in the other experimental conditions. For each experimental condition, seven independent cell culture experiments were performed. Data are expressed as relative luminescence units (RLU) normalized to the total number of alive cells. CTRL condition corresponds to cells exposed to PCB126 only. $\mathrm{R}=$ resveratrol; $\mathrm{A}=\mathrm{AFB1}{ }^{* * *} p<0.001$ (one-way ANOVA, followed by Dunnett's multi-comparisons test).

To further ascertain the impact of $\mathrm{R}$ on the activity of this CYP enzyme, playing a crucial role in AFB1 metabolism, we observed how $R$ alone reduces CYP3A catalytic activity in a dose-dependent way, being $30 \mu \mathrm{M}$ the first significant concentration (Figure S5).

\section{Discussion}

To date, the protective role of R against AFB1 in farm animals has been scarcely studied, and the molecular mechanisms underlying the protective role of this natural polyphenol has never been investigated in depth. A couple of studies have been conducted to elucidate the effects of $\mathrm{R}$ in bovine mammary cells exposed to AFB1 [26,31]. As for the liver, a primary target of AFs toxicity, an in vivo study has been performed in broilers fed with $\mathrm{R}$ in combination with AFB1 [32]. Overall, whole transcriptomic changes resulting from co-treatment with $\mathrm{R}$ and AFs have never been elucidated, not even in mammals.

\subsection{Resveratrol Cytotoxicity}

The $\mathrm{IC}_{50}$ of $\mathrm{R}$ at $64 \mathrm{~h}$ was similar to that reported in bovine mammary cells (BME) experimentally exposed for $48 \mathrm{~h}$ (i.e., approximately $50 \mu \mathrm{M}$ ) [26]. This result is consistent with the $\mathrm{IC}_{50}$ observed at $48 \mathrm{~h}$ in six human cancer cell lines, ranging from 70 to $150 \mu \mathrm{M}$ [69]. Resveratrol cytotoxicity has been recently investigated also in normal cell lines such as the renal tubular epithelial cell line HK-2 and human liver cell line L02, exhibiting an $\mathrm{IC}_{50}$ at $72 \mathrm{~h}$ of approximately 150 and $200 \mu \mathrm{M}$, respectively [70]. A direct comparison between $\mathrm{R} \mathrm{IC}_{50}$ in normal human and bovine hepatocytes cannot be established, because BFH12 are foetal-derived cells; moreover, to our knowledge, no study has yet investigated the cytotoxicity of this natural compound in primary bovine hepatocytes. However, the cytotoxicity data here obtained let us suggest that bovine hepatocytes are more sensitive to 
$\mathrm{R}$ than the human counterpart. Worth of note, when comparing $\mathrm{IC}_{50}$ of different natural antioxidant extracts at $64 \mathrm{~h}$ in BFH12, R shows a cytotoxicity potential similar to that observed for quercetin (Pauletto et al., manuscript in preparation), but considerably lower than those reported for curcuminoids [21].

The significant decrease in AFB1-induced cytotoxicity was crucial in demonstrating the positive impact of $\mathrm{R}$ in cattle, and confirmed the extraordinary potential of this natural extract. In BFH12 exposed to AFB1, curcuminoids were already proven to increase cell viability [21], but such an effect was lower compared to that observed in the present study. In agreement with this study, in BME-UV1 cells $5 \mu \mathrm{M}$ R provided some protection against the cytotoxicity observed after $48 \mathrm{~h}$ of AFB1 exposure $(96 \mathrm{nM})$, increasing cell viability from $40 \%$ up to $60 \%$ [26]. Moreover, in agreement with data we obtained in BFH12, the study by Ghadiri et al. showed a greater ability of $\mathrm{R}$, compared to curcumin, in mitigating AFB1induced cellular death. Such an evidence let us hypothesize that the potential benefits of $\mathrm{R}$ in cattle might be even stronger than curcumin. Considering the higher MDA levels observed in AFB1-treated compared to R and AFB1 co-treated cells, we hypothesize that oxidative stress concurs to increase cell damage and consequently the risk of cell death.

\subsection{Aflatoxin B1 Biotransformation}

The amount of AFM1, the most toxic AFB1 derivative [71], appeared inversely correlated with $\mathrm{R}$ concentrations, as previously observed in BFH12 cells co-treated with curcuminoids and AFB1 [21]. As hypothesized for curcuminoids, it is likely that R reduces AFM1 production by targeting the major enzymes involved in AFM1 hepatic formation [72], and most probably CYP3A. Specifically, CYP3A catalytic activity was enhanced by AFB1 alone, while it was significantly reduced by 30 and $40 \mu \mathrm{M}$ R. Likewise, $\mathrm{R}$ in combination with AFB1 was shown to reverse the mycotoxin-dependent increase in CYP3A enzymatic activity. Overall, these results would suggest CYP3A as the main CYP involved in AFM1 synthesis in BFH12 cells. However, more specific biomolecular studies are needed to confirm such a hypothesis.

Conversely, the amount of highly toxic AFL increased with $\mathrm{R}$ concentration, thus indicating that this natural polyphenol impacts on AFB1 reduction, the reaction forming AFL in the liver [73]. Aflatoxicol can be reconverted to AFB1, thereby serving as a reservoir of AFB1 and thus prolonging the AFB1 residency time in the liver [74]. Despite that, a very recent study demonstrated in poultry species that high rate of AFL production is associated with minor sensitivity to AFB1 [75]. Indeed, the authors postulated that an efficient AFB1 biotransformation to AFL reduces the amount of AFB1 available for bioactivation, thus mitigating the toxicity of AFBO.

Overall, the impact of R on AFM1 and AFL formation seems to be consistent with a beneficial influence of this natural polyphenol.

\subsection{Resveratrol Transcriptional Effects}

Overall, $\mathrm{R}$ administered alone induced neglectable transcriptional changes. Worth of mention, in this same cellular model, curcuminoids had a considerable impact on gene transcription, as they significantly affected the expression of hundreds of genes [21] Notably, curcuminoids were less effective in reducing AFB1-induced toxicity; hence, it is likely that polyphenols that highly perturb BFH12 transcriptional profiles might not be the best choice to improve cell viability.

The most significant DEG was a gene involved in lipid metabolism, the desaturase FADS1, whose transcription was significantly induced by $\mathrm{R}$. This result is consistent with previous literature reporting FADS1 induction in human HepG2 treated with $40 \mu \mathrm{M} R$ [76]. FADS1 plays a role in the synthesis of long chain polyunsaturated fatty acids (PUFA) occurring in liver, and controls the metabolism of inflammatory lipids like prostaglandin E2, critical for efficient acute inflammatory response and maintenance of epithelium homeostasis. Notably, in human melanocytes, FADS1 downregulation induced cell cycle arrest and cell death via ROS generation and mitochondria-mediated apoptosis [77]. Indirectly, this 
evidence let us think that FADS1 induction in BFH12 treated with R might have beneficial effects. Notably, FADS1 induction possibly occurs via a PPAR $\alpha$ activation mediated by R, as previously postulated [52,76,78].

Two key players in inflammatory processes, cell proliferation and survival by regulating apoptosis, i.e., HMGA1 and SPP1 (also known as osteopontin) [79-81], were also induced by $\mathrm{R}$. The former is considered as an oncogene, and its overexpression is a common feature of several human malignancies [82]. Interestingly, an association between the expression of SIRT1, known to be induced by R, and HMGA1 was highlighted in lung cancer [83]. It is not known how the transcriptional increase in this oncogene triggered by R might affect cell functioning, although its association with SIRT1 let us think that it exerts beneficial effects. Intriguingly, it has been hypothesized in rat hepatic stellate cell line (HSC) that the upregulation of HMGA1 occurring after curcumin exposure activates cells senescence, thus preventing fibrogenic response to liver tissue damage [84]. Similarly, we suggest that $\mathrm{R}$ has the same ability in BFH12, and senescence mediated by HMGA1 (together with P53 and PPAR $\gamma$ in rat HSCs) might reduce cell injury. Osteopontin is a crucial player in wound healing processes as it serves as a chemotactic molecule to promote the migration of inflammatory cells to the wound site, where it acts as an adhesive protein to retain cells. For instance, osteopontin has been proposed to be a bone repair mediator, and its transcription was induced in skulls collected from rats treated with $10 \mathrm{mg} / \mathrm{kg} \mathrm{R}$ for 30 days [85]. Likewise, immunohistochemical analyses revealed that $R$ induces osteopontin in rats, and improved alveolar socket healing [86].

The sole gene downregulated by R, SCUBE1, a cell surface glycoprotein found in platelet and endothelial cells [87], was particularly interesting. A very recent study [88] has demonstrated that SCUBE1 is an independent prognostic factor in septic patients, and positive correlates with accepted inflammatory biomarkers and "Acute Physiology And Chronic Health Evaluation II" (APACHE-2), a severity-of-disease classification system [89]. Moreover, accumulation of this protein in blood is associated with vascular dysfunctions like atherosclerotic lesions or ischemic stroke [90], and ovarian impairment [91,92]. Overall, considering the above reported functions of SCUBE1, we suggest that its great downregulation in BFH12 exposed to R (nearly ten times less expressed compared to control) is indicative of very low activation of inflammatory processes.

\subsection{Transcriptional Changes Underlying $R$ Potential as an Anti-AFB1}

If $\mathrm{R}$ alone did not deeply interfere with BFH12 transcriptional patterns, the cotreatment with AFB1 greatly modulated the whole transcriptome when compared to that of cells exposed to AFB1 only. This let us think that the potential of this natural polyphenol is maximal in presence of a stressful event, like AFB1. Indeed, R pre-treatment was effective in counteracting molecular processes triggered by AFB1, and promoting cell survival.

The functional analysis pointed out some interesting pathways underlying the mechanisms by which $\mathrm{R}$ is able to mitigate AFB1-induced toxicity. Among the most significantly enriched BP, we found "lipid biosynthetic process". This term is mainly associated with the tight connection between cholesterol metabolism and inflammation, and is mostly represented by genes whose upregulation aims at decreasing AFB1-induced inflammatory events. Among these ones we found APOA1, PTGIS, and LDLR. The former codes for the major protein component of high-density lipoprotein (HDL), widely known for regulating cholesterol trafficking. It exhibits tumor-suppressive activity by promoting antiinflammatory processes and modulating immune responses $[93,94]$. The second transcript (PTGIS) catalyzes the biosynthesis and metabolism of eicosanoids; its overexpression was reported to prevent the development of murine lung tumors [95], inhibit the activation of HSCs and alleviate liver fibrosis in mice [96]. Finally, LDLR mediates binding and endocytosis of low-density lipoproteins (LDLs), and it has been previously found to be upregulated by $\mathrm{R}$ in cultured hepatocytes $[97,98]$. As oxidized LDLs is a marker of inflam- 
mation, the overexpression of this receptor, eliminating LDLs, might be considered as a beneficial and anti-inflammatory molecular event in BFH12 co-treated with R and AFB1.

Two out of the 5 downregulated genes representing the lipid biosynthesis term (i.e., PLA2G4A and TM7SF2) were most likely implicated in mitigating the inflammatory response, thus reducing cell injury. The former gene (PLA2G4A) encodes for an enzyme that catalyzes the hydrolysis of membrane phospholipids to release arachidonic acid, a hinge molecule in eicosanoids synthetic pathway. Eicosanoids are lipid-based cellular hormones key for the inflammatory response. Notably, in rat mesangial cells pre-treated with $\mathrm{R}$ derivatives and stimulated with the pro-inflammatory cytokine TNF- $\alpha$, Lee et al. reported an inhibition of PLA2G4A protein expression, thus suggesting an anti-inflammatory activity of these natural compounds [99]. Likewise, in our previous study, we observed a transcriptional decrease in PLA2G4A in BFH12 pre-treated with curcumin and exposed to AFB1 [21]. A dual activity has been proposed for TM7SF2; besides actively participating in cholesterol biosynthesis, it might be linked to the cellular response to endoplasmic reticulum stressors [100]. Its downregulation might be indicative of an anti-inflammatory response triggered by R pre-treatment. A similar hypothesis has been drawn by Gatticchi et al., who observed in TM7SF2 knockout mice that the gene deficiency is responsible in kidney for the inhibition of the signalling mediated by the nuclear factor kappa-light-chainenhancer of activated B cells (NFkB), thus dampening the inflammatory response induced by LPS and leading to a reduced renal damage [101].

The enriched BP "response to external stimulus" was represented by some key genes which provide additional information about the molecular mechanisms underlying the $\mathrm{R}$ protective role against AFB1-induced toxicity in BFH12. For instance, AQP1 (upregulated by $\mathrm{R}$ ) might exert a cytoprotective role and help to alleviate the inflammatory reaction induced by AFB1. Its overexpression has been previously suggested to confer survival advantage in LPS-induced acute kidney injury, both in vivo in rats [102]) and in vitro in human proximal tubule cell line [103]. Similarly, FOS, a key regulator in inflammation, apoptosis and the immune system, was induced by R. Interestingly, in macrophages FOS suppresses the expression of inducible nitric oxide synthase and pro-inflammatory cytokines (e.g., TNF- $\alpha$ ), and increase the expression of anti-inflammatory genes, such as suppressor of cytokine signalling 3 (SOCS3) [104], whose mRNA was upregulated by R also in our cell model. Notably, in human embryonic kidney 293 cells, CACO-2 cells, and murine C17.2 neural stem cells, the transcription of FOS protooncogene was reported to be stimulated by $20 \mu \mathrm{M} R$ [105]. The transcription receptor NR1H4 (also known as Farnesoid X Receptor, FXR), regulating the inflammatory response and greatly expressed in liver, was largely overexpressed in AFB1-exposed cells pre-treated with R. The significance upregulation of FXR in the present study might be related to the anti-inflammatory activity of this transcription factor. In fact, FXR has been previously shown to confer protection in several animal models of innate intestinal and hepatic inflammation [106]. A similar role is most likely exerted by SERPING1 (also known as C1INH) and FNDC4, both upregulated by $\mathrm{R}$ in BFH12. The former is a complement inhibitor that has demonstrated the ability to effectively reduce complement activation, thus dampening tissue inflammatory reactions, both in vivo and in vitro in pig liver [107]. The latter codes for a secreted protein recently proven to act as an anti-inflammatory factor in mouse intestine and colon [108]. In our study, FNDC4 was downregulated in BFH12 cells exposed to AFB1 [63], but a pre-treatment with $\mathrm{R}$ enhanced its transcription, that most likely improved cell survival, and downregulated the expression of pro-inflammatory genes. Accordingly, we found the same pattern of expression in BFH12 pre-treated with curcumin [21].

In the presence of R, CXCR3 ligands (CXCL9, CXCL10, and CXCL11), that are proinflammatory cytokines, were upregulated. Interestingly, CXCL10 (the IFN-inducible protein-10/IP-10) is a general marker of hepatic inflammation and injury, but it has also shown hepatoprotective effects in mice, as it plays a role in hepatic repair and regeneration $[109,110]$. However, this result is in contrast with other studies reporting that the transcriptional inhibition of these genes, mediated by natural extracts, might have a 
protective role in liver. For instance, in mice a decrease in CXCL10 production has been suggested to partly account for the inhibitory effect of curcumin on CD4+ T cells infiltration in the liver [111]. Furthermore, in human retinal pigment epithelium cells treated with pro-inflammatory cytokines, a pre-treatment with $50 \mu \mathrm{M}$ R inhibited the expression of CXCL9 and CXCL11 [112]. In vivo, a higher CXCL9 and CXCL10 expression was associated with animals with the greatest degree of liver injury $[113,114]$. Nonetheless, it should be noted that the expression of these cytokines might change over time during liver injury, and these changes are crucial in determining the fate of cells, as hypothesized in vivo in human serum [115]. Notably, in a previous study we demonstrated that in BFH12 exposed to AFB1 the expression of CXCR3 ligands was largely downregulated [63]. Here, we show that $\mathrm{R}$ reverts this trend of expression, and this let us think that CXCL9, CXCL10, and CXCL11 induction by R somehow counteracts AFB1 toxic effects. More research is needed to shed light in the role of these important pro-inflammatory cytokines in mediating $\mathrm{R}$ anti-AFB1 activity in cattle.

Some interesting genes involved in cancer development and invasion, and belonging to the $\mathrm{BP}$ "response to external stimulus" were downregulated by $\mathrm{R}$, thus suggesting that $\mathrm{R}$ might attenuate the activation of biological processes normally triggered by AFB1 stimulus and responsible of the hepatocarcinogenicity of this mycotoxin. This is the case of ALCAM (also known as CD166), SEMA3C, and OMA1. The first gene is a cell surface member of the immunoglobulin superfamily playing a pro-carcinogenic role in liver cancer [116]; interestingly, it has been reported to be inhibited in vitro by dietary polyphenols like curcumin [117]. The metastasis marker SEMA3C [118] is correlated with chronic hepatitis and significant fibrosis in human liver, too [119]. To our knowledge, ALCAM and SEMA3C have not been reported to be associated with mycotoxins toxicity. However, as in human liver cells an increase in their expression is involved in hepatic diseases, we might hypothesize that their downregulation by $\mathrm{R}$ is a beneficial effect that protects cells from AFB1-induced damage. Finally, OMA1, that was significantly downregulated by R, might be crucial in mitigating AFB1-induced toxicity, since it is a major mitochondrial factor for sensing and responding to cellular stress [120], including oxidative stress [121]. Moreover, OMA1 is responsible of optic atrophy-1 (OPA1) cleavage and mitochondrial fragmentation induced by $\mathrm{H}_{2} \mathrm{O}_{2}$, and mammalian cells lacking OMA1 showed protection against this mitochondrial stress [121]. In agreement with the present results, $\mathrm{R}$ reversed the increased mRNA levels of OMA1 observed in rat retina 7 days after ischemia/reperfusion injury [122]. Again, OMA1 has never been linked to AFB1. The evidence that lowering, or completely abolishing, the transcription of this gene provides protection from different oxidative stress in diverse mammalian cells, let us suggest that OMA1 downregulation triggered by $\mathrm{R}$ in BFH12 cells concurs to mitigate the detrimental effects of AFB1.

Careful analysis of the list of up- and downregulated genes pointed out some additional interesting mRNA changes triggered by $\mathrm{R}$ that most likely contribute to prevent cell damage and death occurring in cells exposed to AFB1.

For instance, CYP1B1 and CYP1A1 were both more expressed in cells co-treated with R and AFB1 compared to those treated with AFB1 only. Notably, if compared to control cells, the expression of these genes was significantly re-pressed by AFB1 [63]. Interestingly, both curcumin [21] and R showed the ability to revert the pattern of expression of CYP1A1 in $\mathrm{BFH12}$. This let us suggest that an increased expression of this gene is a positive signature. Yet, it is possible that the activity of this enzyme is further regulated at a post-transcriptional level (e.g., protein translation, catalytic activity). Despite this, our previous investigations in BFH12 [21,63], and the changes triggered by R on CYP3A mRNA (not significant) and catalytic activity (significantly decreased) led us to hypothesize that CYP3A4, rather than CYP1A1, has a prominent role in AFB1 biotransformation. Moreover, if curcumin impacted both CYP3A expression and activity, $R$ seems to target the activity of this enzyme, but not its transcription. This is in agreement with a previous study suggesting that $\mathrm{R}$ is a mechanism-based inactivator of human CYP3A4 [123]. The cytochrome P450 $26 \mathrm{~B} 1$ was the unique CYP downregulated by $\mathrm{R}$, but it is not considered a classic xenobiotic metabolizing 
enzyme. Intriguingly, the expression of this gene was largely reduced also in BFH12 cotreated with curcumin [21], thus paving the idea that CYP26B1 might play an important role in BFH12 response to AFB1.

BFH12 pre-treated with R and then exposed to AFB1 exhibited transcriptional changes in some genes implicated in the antioxidant response and detoxification. Transferrin (TF), glutathione peroxidase 7 (GPX7), and peroxidasin (PXDN) were all significantly upregulated by R, while SOD2 was downregulated. Transferrin sequestrates iron, that produces free radicals, in a redox-inactive form, thus possessing an antioxidant capacity and providing a cytoprotective effect in various animal models [124]. Glutathione peroxidase hampers the accumulation of ROS in cells, and it participates in the correct protein folding as an intracellular stress sensor/transmitter to transfer the signal to its interacting proteins [125]. Similar to GPX7, GPX1 counteracts oxidative stress, but its transcription was inhibited by $R$, yet with marginal significance (FDR $=0.07$ ). This result is in opposition with most of the published literature, highlighting a protective role of GPX1 induction under stressful conditions; but it is consistent with what we have observed in BFH12 co-treated with curcumin and AFB1 [21], suggesting shared molecular mechanism between these different natural polyphenols. Peroxidasin facilitates peroxidative reactions as it generates hypohalous acids by catalysing $\mathrm{H}_{2} \mathrm{O}_{2}$, and it is a target of NRF2 [126]. Notably, PXDN scavenges $\mathrm{H}_{2} \mathrm{O}_{2}$ in cardiovascular tissue, and it prevents oxidative stress in prostate cancer in vitro [127]. The downregulation of SOD2 is in contrast with most of studies assessing $\mathrm{R}$ transcriptional effects and reporting a significant induction of this mitochondrial enzyme [128-130]. However, this result is consistent with the effects induced by curcumin in the same cell model exposed to AFB1 [21], thus suggesting a peculiar transcriptional regulation for this crucial enzyme in bovine liver. Conversely, SOD1 was not significantly modulated by R. Notably, in the present study we focused on transcriptional modifications, but post-transcriptional regulations are likely to occur and affect the cells antioxidant capacity mediated by these enzymes.

Genes involved in detoxification were also significantly impacted by R. For instance, the microsomal glutathione S-transferase 1 (MGST1) was significantly induced by R and AFB1 co-treatment. This gene has a well-established role in the conjugation of electrophiles and oxidative stress protection [131]. Worth of note, its transcription was lower in BFH12 treated with AFB1 than in control cells [63], and, likewise to cells pre-treated with R, curcumin pre-treatment prevented AFB1-induced downregulation of this gene [21]. Nonetheless, in swine the placental mRNA expression of MGST1 was increased by dietary R [132]. Besides MGST1, glutathione S-transferase A2 (GSTA2) showed the same transcriptional behavior, but the corrected $p$-value was minimally below the threshold of significance $(\mathrm{FDR}=0.056)$. This gene targets the same compounds of MGST1, including carcinogens, environmental toxins, and products of oxidative stress, by conjugation with glutathione. Overall, their transcriptional induction by $\mathrm{R}$ contribute to AFB1 detoxification and antioxidant mechanisms of response. Interestingly, in human and mice MGST1 and GSTA2 gene expression is regulated by NRF2 [133-135], a master regulator of the antioxidant response, whose expression was not significantly regulated in the present experiment. Based on our experience with this cell line, this is not particularly unexpected, since a similar transcriptional pattern was observed following the exposure to curcumin [21]. Conversely, the gene expression of NRF2 downstream genes (such as GSTs) appeared to be significantly affected. Therefore, it is likely that, in BFH12 cells, the polyphenols we tested might target NRF2 by affecting its protein synthesis and/or activity, rather than its level of transcription. Notably, some additional results let us suggest that $\mathrm{R}$ exerts it anti-AFB1 activity by regulating post transcriptionally some key genes. Pivotal examples could be NQO1 and CYP3A. Resveratrol greatly impacted their enzymatic activity, providing a protective mechanism against AFB1, but it did not affect their transcription at all.

As for the $A B C$ transporters, $A B C A 1$, multidrug-resistant protein 1 (MDR1), and ABCG2, showed a transcriptional pattern similar to that observed after curcumin pretreatment: $\mathrm{ABCA} 1$ and MDR1 were downregulated, while ABCG2 was upregulated by 
$\mathrm{R}$ [21]. The downregulation of ABCA1, a transporter involved in the cholesterol efflux from cells and primarily responsible for the initiation of HDL formation, is in opposition to what reported in the literature. In fact, in human cell models, $\mathrm{R}$ was reported to promote the expression of cholesterol efflux proteins like ABCA1 [136]. Conversely, the downregulation of MDR1 by R, both at mRNA and protein level, has already been demonstrated in the context of drug-resistant cancer cells [137]. The present data do not allow us to clarify the role of MDR1 in cattle liver; however, it seems unlikely for this gene playing a prominent role in the AFB1 detoxification process [138]. Aflatoxins are ligands for ABCG2 and they have been demonstrated to affect the expression of this transporter [139]. A recent study conducted in bovine mammary epithelial cells (BMEs) has also demonstrated that ABCG2 (also known as breast cancer resistance protein, BCRP) is able to transport AFM1 [140]. The detailed mechanism of the aflatoxins transport by ABCG2 is still uncertain in cattle; however, ABCG2 upregulation might mitigate AFB1 toxicity decreasing its cellular uptake, as previously demonstrated in MDCK-II cells transduced with ABCG2 [139].

\section{Conclusions}

To the best of our knowledge, this is the first study assessing the potential benefits of $\mathrm{R}$ in AFB1-exposed bovine cells through an integrated approach encompassing cytotoxicity, whole-transcriptomics, and specific post-transcriptional confirmatory assays. Based on the present results, and the experiments that we have previously performed on this cell model, the following conclusions can be drawn. (1) Resveratrol pre-treatment hampered AFB1induced cytotoxicity. (2) Resveratrol treatment scarcely affected the BFH12 transcriptome. (3) Resveratrol pre-treatment deeply modified the transcriptome of BFH12 cells exposed to AFB1. (4) The pathways mostly affected by R pre-treatment, and driving protective mechanisms against AFB1 toxicity, are related to lipid biosynthetic processes, inflammation, drug metabolism, and drug transport. (5) Prospective molecular studies are recommended to investigate the role played by specific pathways/genes in AFB1 mechanistic toxicology and, consequently, better characterize the protective role of R. (6) In vivo studies implementing $\mathrm{R}$-supplemented diets are envisaged to assess R's bioavailability and its beneficial effects on aflatoxicosis. (7) Compared to curcuminoids, $\mathrm{R}$ showed a greater potential to mitigate AFB1-induced toxicity; this suggests that $R$ might be a better choice for further in vivo investigations assessing the introduction of this polyphenol in dairy cattle feeding strategies. Indeed, we expect that the beneficial effects, and the underneath molecular mechanisms, might occur also in vivo, yet with slight differences. Thus, in perspective, R-supplemented diets might improve health status of cattle exposed to AFB1-contaminated feed.

Supplementary Materials: The following are available online at https://www.mdpi.com/article/ 10.3390/antiox10081225/s1, Figure S1: Chemicals, Figure S2: Biotransformation of AFB1 in BFH12 cells, Figure S3. Real-time PCR: transcriptional changes induced by R, Figure S4. MDS plot, Figure S5. Dose dependent effects of resveratrol on CYP3A activity, Table S1. Sequencing and mapping results, Table S2. Differential expression analysis, Table S3. Over-representation analysis, Table S4. Gene Set Enrichment Analysis (KEGG pathways), File S1. R code.

Author Contributions: Conceptualization, M.P., M.G. and M.D.; Data curation, M.P.; Formal analysis, M.P., M.G. and A.B.; Funding acquisition, M.P., A.Z. and M.D.; Investigation, M.P., M.G., R.T., I.B. and A.B.; Methodology, M.P., M.G. and A.B.; Supervision, M.D.; Writing—original draft, M.P.; Writingreview and editing, M.G., A.B., A.Z. and M.D. All authors have read and agreed to the published version of the manuscript.

Funding: This research was supported by (i) a grant to M.D. from the Italian Ministry of Education, Universities and Research (MIUR), Project of national interest (PRIN) 2015, "Effects of curcuminoids on the toxicity and mammary excretion of Aflatoxins (B1 and B2) and their metabolites in dairy cows", (ii) a grant to M.P. from the University of Padova ("DOR2019—prot. DOR1917008").

Institutional Review Board Statement: Not applicable.

Informed Consent Statement: Not applicable. 
Data Availability Statement: Raw Illumina sequencing data have been deposited in GenBank (SRA) under the BioProject accession PRJNA627332.

Acknowledgments: Authors are grateful to Axel Schoeniger (Institute of Biochemistry, University of Leipzig, Germany) who provided the BFH12 cell line.

Conflicts of Interest: The authors declare no conflict of interest.

\section{References}

1. Monbaliu, S.; Van Poucke, C.; Detavernier, C.; Dumoulin, F.; Van De Velde, M.; Schoeters, E.; Van Dyck, S.; Averkieva, O.; Van Peteghem, C.; De Saeger, S. Occurrence of Mycotoxins in Feed as Analyzed by a Multi-Mycotoxin LC-MS/MS Method. J. Agric. Food Chem. 2010, 58, 66-71. [CrossRef]

2. Streit, E.; Schatzmayr, G.; Tassis, P.; Tzika, E.; Marin, D.; Taranu, I.; Tabuc, C.; Nicolau, A.; Aprodu, I.; Puel, O.; et al. Current Situation of Mycotoxin Contamination and Co-Occurrence in Animal Feed-Focus on Europe. Toxins 2012, 4, 788-809. [CrossRef]

3. Monson, M.S.; Settlage, R.E.; McMahon, K.W.; Mendoza, K.M.; Rawal, S.; El-Nezami, H.S.; Coulombe, R.A.; Reed, K.M. Response of the Hepatic Transcriptome to Aflatoxin B1in Domestic Turkey (Meleagris Gallopavo). PLoS ONE 2014. [CrossRef]

4. Rustemeyer, S.M.; Lamberson, W.R.; Ledoux, D.R.; Wells, K.; Austin, K.J.; Cammack, K.M. Effects of Dietary Aflatoxin on the Hepatic Expression of Apoptosis Genes in Growing Barrows. J. Anim. Sci. 2011. [CrossRef]

5. Shi, F.; Seng, X.; Tang, H.; Zhao, S.; Deng, Y.; Jin, R.; Li, Y. Effect of Low Levels of Aflatoxin B1 on Performance, Serum Biochemistry, Hepatocyte Apoptosis and Liver Histopathological Changes of Cherry Valley Ducks. J. Anim. Vet. Adv. 2013, 12, 1126-1130. [CrossRef]

6. Rawal, S.; Kim, J.E.; Coulombe, R. Aflatoxin B1 in Poultry: Toxicology, Metabolism and Prevention. Res. Vet. Sci. 2010, 89, 325-331. [CrossRef] [PubMed]

7. Wu, F.; Guclu, H. Aflatoxin Regulations in a Network of Global Maize Trade. PLoS ONE 2012, 7, e45151. [CrossRef] [PubMed]

8. Deng, J.; Zhao, L.; Zhang, N.Y.; Karrow, N.A.; Krumm, C.S.; Qi, D.S.; Sun, L.H. Aflatoxin B 1 Metabolism: Regulation by Phase I and II Metabolizing Enzymes and Chemoprotective Agents. Mutat. Res. Rev. Mutat. Res. 2018, 778, 79-89. [CrossRef]

9. IARC. IARC Monographs on the Evaluation of Carcinogenic Risks to Humans; Internal Report 14/002; IARC: Lyon, France, 2010; Volume 93, pp. 9-38. [CrossRef]

10. Yilmaz, S.; Kaya, E.; Kisacam, M.A. The Effect on Oxidative Stress of Aflatoxin and Protective Effect of Lycopene on Aflatoxin Damage. In Aflatoxin-Control, Analysis, Detection and Health Risks; Abdulra'uf, L.B., Ed.; InTech: London, UK, 2017.

11. Prandini, A.; Tansini, G.; Sigolo, S.; Filippi, L.; Laporta, M.; Piva, G. On the Occurrence of Aflatoxin M1 in Milk and Dairy Products. Food Chem. Toxicol. 2009, 47, 984-991. [CrossRef]

12. Dohnal, V.; Wu, Q.; Kuča, K. Metabolism of Aflatoxins: Key Enzymes and Interindividual as Well as Interspecies Differences. Arch. Toxicol. 2014, 88, 1635-1644. [CrossRef]

13. Fink-Gremmels, J. Mycotoxins in Cattle Feeds and Carry-over to Dairy Milk: A Review. Food Addit. Contam. Part A 2008, 25, 172-180. [CrossRef]

14. Gallo, A.; Giuberti, G.; Frisvad, J.C.; Bertuzzi, T.; Nielsen, K.F. Review on Mycotoxin Issues in Ruminants: Occurrence in Forages, Effects of Mycotoxin Ingestion on Health Status and Animal Performance and Practical Strategies to Counteract Their Negative Effects. Toxins 2015, 7, 3057-3111. [CrossRef] [PubMed]

15. Elgioushy, M.M.; Elgaml, S.A.; El-Adl, M.M.; Hegazy, A.M.; Hashish, E.A. Aflatoxicosis in Cattle: Clinical Findings and Biochemical Alterations. Environ. Sci. Pollut. Res. 2020, 27, 35526-35534. [CrossRef]

16. Council for Agricultural Science and Technology. Mycotoxins: Risks in Plant, Animal, and Human Systems; Task Force Report; Council for Agricultural Science and Technology: Ames, IA, USA, 2003; ISBN 978-1-887383-22-6.

17. Marin, D.E.; Taranu, I. Overview on Aflatoxins and Oxidative Stress. Toxin Rev. 2012, 31, 32-43. [CrossRef]

18. Mavrommatis, A.; Giamouri, E.; Tavrizelou, S.; Zacharioudaki, M.; Danezis, G.; Simitzis, P.E.; Zoidis, E.; Tsiplakou, E.; Pappas, A.C.; Georgiou, C.A.; et al. Impact of Mycotoxins on Animals' Oxidative Status. Antioxidants 2021, 10, 214. [CrossRef]

19. Benkerroum, N. Chronic and Acute Toxicities of Aflatoxins: Mechanisms of Action. Int. J. Environ. Res. Public Health 2020, 17, 423. [CrossRef]

20. Da Silva, E.O.; Bracarense, A.P.F.L.; Oswald, I.P. Mycotoxins and Oxidative Stress: Where Are We? World Mycotoxin J. 2018, 11, 113-134. [CrossRef]

21. Pauletto, M.; Giantin, M.; Tolosi, R.; Bassan, I.; Barbarossa, A.; Zaghini, A.; Dacasto, M. Curcumin Mitigates AFB1-Induced Hepatic Toxicity by Triggering Cattle Antioxidant and Anti-Inflammatory Pathways: A Whole Transcriptomic In Vitro Study. Antioxidants 2020, 9, 1059. [CrossRef]

22. Limaye, A.; Yu, R.C.; Chou, C.C.; Liu, J.R.; Cheng, K.C. Protective and Detoxifying Effects Conferred by Dietary Selenium and Curcumin against AFB1-Mediated Toxicity in Livestock: A Review. Toxins 2018, 10, 25. [CrossRef]

23. Li, S.; Muhammad, I.; Yu, H.; Sun, X.; Zhang, X. Detection of Aflatoxin Adducts as Potential Markers and the Role of Curcumin in Alleviating AFB1-Induced Liver Damage in Chickens. Ecotoxicol. Environ. Saf. 2019, 176, 137-145. [CrossRef]

24. El-Mekkawy, H.I.; Al-Kahtani, M.A.; Shati, A.A.; Alshehri, M.A.; Al-Doaiss, A.A.; Elmansi, A.A.; Ahmed, A.E. Black Tea and Curcumin Synergistically Mitigate the Hepatotoxicity and Nephropathic Changes Induced by Chronic Exposure to Aflatoxin-B1 in Sprague-Dawley Rats. J. Food Biochem. 2020, 44. [CrossRef] [PubMed] 
25. Solis-Cruz, B.; Hernandez-Patlan, D.; Petrone, V.; Pontin, K.; Latorre, J.; Beyssac, E.; Hernandez-Velasco, X.; Merino-Guzman, R.; Owens, C.; Hargis, B.; et al. Evaluation of Cellulosic Polymers and Curcumin to Reduce Aflatoxin B1 Toxic Effects on Performance, Biochemical, and Immunological Parameters of Broiler Chickens. Toxins 2019, 11, 121. [CrossRef]

26. Ghadiri, S.; Spalenza, V.; Dellafiora, L.; Badino, P.; Barbarossa, A.; Dall'Asta, C.; Nebbia, C.; Girolami, F. Modulation of Aflatoxin B1 Cytotoxicity and Aflatoxin M1 Synthesis by Natural Antioxidants in a Bovine Mammary Epithelial Cell Line. Toxicol. Vitr. 2019. [CrossRef]

27. Taranu, I.; Marin, D.E.; Palade, M.; Pistol, G.C.; Chedea, V.S.; Gras, M.A.; Rotar, C. Assessment of the Efficacy of a Grape Seed Waste in Counteracting the Changes Induced by Aflatoxin B1 Contaminated Diet on Performance, Plasma, Liver and Intestinal Tissues of Pigs after Weaning. Toxicon 2019. [CrossRef] [PubMed]

28. Marin, D.E.; Bulgaru, C.V.; Anghel, C.A.; Pistol, G.C.; Dore, M.I.; Palade, M.L.; Taranu, I. Grape Seed Waste Counteracts Aflatoxin B1 Toxicity in Piglet Mesenteric Lymph Nodes. Toxins 2020, 12, 800. [CrossRef] [PubMed]

29. Taranu, I.; Hermenean, A.; Bulgaru, C.; Pistol, G.C.; Ciceu, A.; Grosu, I.A.; Marin, D.E. Diet Containing Grape Seed Meal By-Product Counteracts AFB1 Toxicity in Liver of Pig after Weaning. Ecotoxicol. Environ. Saf. 2020, 203, 110899. [CrossRef]

30. Rawat, D.; Chhonker, S.K.; Naik, R.A.; Koiri, R.K. Modulation of Antioxidant Enzymes, SIRT1 and NF-kB by Resveratrol and Nicotinamide in Alcohol-aflatoxin B1-induced Hepatocellular Carcinoma. J. Biochem. Mol. Toxicol. 2021, 35. [CrossRef]

31. Zhou, Y.; Jin, Y.; Yu, H.; Shan, A.; Shen, J.; Zhou, C.; Zhao, Y.; Fang, H.; Wang, X.; Wang, J.; et al. Resveratrol Inhibits Aflatoxin B1-Induced Oxidative Stress and Apoptosis in Bovine Mammary Epithelial Cells and Is Involved the Nrf2 Signaling Pathway. Toxicon 2019, 164, 10-15. [CrossRef]

32. Sridhar, M.; Suganthi, R.U.; Thammiaha, V. Effect of Dietary Resveratrol in Ameliorating Aflatoxin B1-Induced Changes in Broiler Birds. J. Anim. Physiol. Anim. Nutr. 2015, 99, 1094-1104. [CrossRef]

33. Feng, M.; Zhong, L.-X.; Zhan, Z.-Y.; Huang, Z.-H.; Xiong, J.-P. Resveratrol Treatment Inhibits Proliferation of and Induces Apoptosis in Human Colon Cancer Cells. Med. Sci. Monit. 2016, 22, 1101-1108. [CrossRef]

34. Wahab, A.; Gao, K.; Jia, C.; Zhang, F.; Tian, G.; Murtaza, G.; Chen, J. Significance of Resveratrol in Clinical Management of Chronic Diseases. Molecules 2017, 22, 1329. [CrossRef] [PubMed]

35. Martí-Centelles, R.; Murga, J.; Falomira, E.; Carda, M.; Marco, J.A. Synthesis and Biological Evaluation of Imines Structurally Related to Resveratrol as Dual Inhibitors of VEGF Protein Secretion and HTERT Gene Expression. Nat. Prod. Commun. 2017, 12, 699-703. [CrossRef] [PubMed]

36. Zhang, W.; Yu, H.; Lin, Q.; Liu, X.; Cheng, Y.; Deng, B. Anti-Inflammatory Effect of Resveratrol Attenuates the Severity of Diabetic Neuropathy by Activating the Nrf2 Pathway. Aging 2021, 13, 10659-10671. [CrossRef]

37. Hecker, A.; Schellnegger, M.; Hofmann, E.; Luze, H.; Nischwitz, S.P.; Kamolz, L.; Kotzbeck, P. The Impact of Resveratrol on Skin Wound Healing, Scarring, and Aging. Int. Wound J. 2021. [CrossRef]

38. Bishayee, A.; Politis, T.; Darvesh, A.S. Resveratrol in the Chemoprevention and Treatment of Hepatocellular Carcinoma. Cancer Treat. Rev. 2010, 36, 43-53. [CrossRef]

39. Timmers, S.; Konings, E.; Bilet, L.; Houtkooper, R.H.; van de Weijer, T.; Goossens, G.H.; Hoeks, J.; van der Krieken, S.; Ryu, D.; Kersten, S.; et al. Calorie Restriction-like Effects of 30 Days of Resveratrol Supplementation on Energy Metabolism and Metabolic Profile in Obese Humans. Cell Metab. 2011, 14, 612-622. [CrossRef] [PubMed]

40. Zhang, C.; Luo, J.; Yu, B.; Chen, J.; Chen, D. Effects of Resveratrol on Lipid Metabolism in Muscle and Adipose Tissues: A Reevaluation in a Pig Model. J. Funct. Foods 2015, 14, 590-595. [CrossRef]

41. Al-Hussaini, H.; Kittaneh, R.S.; Kilarkaje, N. Effects of Trans-Resveratrol on Type 1 Diabetes-Induced up-Regulation of Apoptosis and Mitogen-Activated Protein Kinase Signaling in Retinal Pigment Epithelium of Dark Agouti Rats. Eur. J. Pharmacol. 2021, 904, 174167. [CrossRef]

42. Zhang, C.; Yang, L.; Zhao, X.; Chen, X.; Wang, L.; Geng, Z. Effect of Dietary Resveratrol Supplementation on Meat Quality, Muscle Antioxidative Capacity and Mitochondrial Biogenesis of Broilers: Resveratrol on Meat Quality, Muscle Antioxidative Capacity and Mitochondrial Biogenesis. J. Sci. Food Agric. 2018, 98, 1216-1221. [CrossRef] [PubMed]

43. Mohebodini, H.; Jazi, V.; Bakhshalinejad, R.; Shabani, A.; Ashayerizadeh, A. Effect of Dietary Resveratrol Supplementation on Growth Performance, Immune Response, Serum Biochemical Indices, Cecal Microflora, and Intestinal Morphology of Broiler Chickens Challenged with Escherichia Coli. Livest. Sci. 2019, 229, 13-21. [CrossRef]

44. Meng, Q.; Sun, S.; Bai, Y.; Luo, Z.; Li, Z.; Shi, B.; Shan, A. Effects of Dietary Resveratrol Supplementation in Sows on Antioxidative Status, Myofiber Characteristic and Meat Quality of Offspring. Meat Sci. 2020, 167, 108176. [CrossRef]

45. Qiu, Y.; Yang, J.; Wang, L.; Yang, X.; Gao, K.; Zhu, C.; Jiang, Z. Dietary Resveratrol Attenuation of Intestinal Inflammation and Oxidative Damage Is Linked to the Alteration of Gut Microbiota and Butyrate in Piglets Challenged with Deoxynivalenol. J. Anim. Sci. Biotechnol. 2021, 12, 71. [CrossRef]

46. Averilla, J.N.; Oh, J.; Wu, Z.; Liu, K.; Jang, C.H.; Kim, H.J.; Kim, J.-S.; Kim, J.-S. Improved Extraction of Resveratrol and Antioxidants from Grape Peel Using Heat and Enzymatic Treatments. J. Sci. Food Agric. 2019, 99, 4043-4053. [CrossRef] [PubMed]

47. Jin, S.; Luo, M.; Wang, W.; Zhao, C.; Gu, C.; Li, C.; Zu, Y.; Fu, Y.; Guan, Y. Biotransformation of Polydatin to Resveratrol in Polygonum Cuspidatum Roots by Highly Immobilized Edible Aspergillus Niger and Yeast. Bioresour. Technol. 2013, 136, 766-770. [CrossRef] [PubMed] 
48. Sun, B.; Zheng, Y.-L.; Yang, S.-K.; Zhang, J.-R.; Cheng, X.-Y.; Ghiladi, R.; Ma, Z.; Wang, J.; Deng, W.-W. One-Pot Method Based on Deep Eutectic Solvent for Extraction and Conversion of Polydatin to Resveratrol from Polygonum Cuspidatum. Food Chem. 2021, 343, 128498. [CrossRef] [PubMed]

49. Hao, D.; Wang, X.; Wang, X.; Thomsen, B.; Kadarmideen, H.N.; Lan, X.; Huang, Y.; Chen, H. Transcriptomic Changes in Bovine Skeletal Muscle Cells after Resveratrol Treatment. Gene 2020, 754, 144849. [CrossRef]

50. Mendes, K.L.; Lelis, D.d.F.; Santos, S.H.S. Nuclear Sirtuins and Inflammatory Signaling Pathways. Cytokine Growth Factor Rev. 2017, 38, 98-105. [CrossRef] [PubMed]

51. Singh, C.K.; Chhabra, G.; Ndiaye, M.A.; Garcia-Peterson, L.M.; Mack, N.J.; Ahmad, N. The Role of Sirtuins in Antioxidant and Redox Signaling. Antioxid. Redox Signal. 2018, 28, 643-661. [CrossRef] [PubMed]

52. Mohar, D.S. The Sirtuin System: The Holy Grail of Resveratrol? J. Clin. Exp. Cardiol. 2012, 3. [CrossRef]

53. Li, C.-Y.; Zhao, Y.-H.; Hao, H.-S.; Wang, H.-Y.; Huang, J.-M.; Yan, C.-L.; Du, W.-H.; Pang, Y.-W.; Zhang, P.-P.; Liu, Y.; et al. Resveratrol Significantly Improves the Fertilisation Capacity of Bovine Sex-Sorted Semen by Inhibiting Apoptosis and Lipid Peroxidation. Sci. Rep. 2018, 8, 7603. [CrossRef] [PubMed]

54. Jin, X.; Wang, K.; Liu, H.; Hu, F.; Zhao, F.; Liu, J. Protection of Bovine Mammary Epithelial Cells from Hydrogen Peroxide-Induced Oxidative Cell Damage by Resveratrol. Oxid. Med. Cell. Longev. 2016, 2016, 1-15. [CrossRef] [PubMed]

55. Zheng, Y.; Wu, W.; Hu, G.; Qiu, L.; Chen, J. Transcriptome Analysis of Juvenile Tilapia (Oreochromis Niloticus) Blood, Fed With Different Concentrations of Resveratrol. Front. Physiol. 2020, 11, 600730. [CrossRef]

56. Meng, Q.; Sun, S.; Luo, Z.; Shi, B.; Shan, A.; Cheng, B. Maternal Dietary Resveratrol Alleviates Weaning-Associated Diarrhea and Intestinal Inflammation in Pig Offspring by Changing Intestinal Gene Expression and Microbiota. Food Funct. 2019, 10, 5626-5643. [CrossRef] [PubMed]

57. Zhang, C.; Wang, L.; Zhao, X.H.; Chen, X.Y.; Yang, L.; Geng, Z.Y. Dietary Resveratrol Supplementation Prevents TransportStress-Impaired Meat Quality of Broilers through Maintaining Muscle Energy Metabolism and Antioxidant Status. Poult. Sci. 2017, 96, 2219-2225. [CrossRef]

58. Rawat, D.; Shrivastava, S.; Naik, R.A.; Chhonker, S.K.; Koiri, R.K. SIRT1-mediated Amelioration of Oxidative Stress in Kidney of Alcohol-aflatoxin-B1-induced Hepatocellular Carcinoma by Resveratrol Is Catalase Dependent and GPx Independent. J. Biochem. Mol. Toxicol. 2020, 34. [CrossRef]

59. Wu, J.; Gan, Z.; Zhuo, R.; Zhang, L.; Wang, T.; Zhong, X. Resveratrol Attenuates Aflatoxin B1-Induced ROS Formation and Increase of M6A RNA Methylation. Animals 2020, 10, 677. [CrossRef]

60. Omur, A.; Yildirim, B.; Saglam, Y.; Comakli, S.; Ozkaraca, M. Activity of Resveratrol on the Influence of Aflatoxin B1 on the Testes of Sprague Dawley Rats. Pol. J. Vet. Sci. 2019, 22, 313-320. [CrossRef]

61. El-Agamy, D.S. Comparative Effects of Curcumin and Resveratrol on Aflatoxin B1-Induced Liver Injury in Rats. Arch. Toxicol. 2010, 84, 389-396. [CrossRef] [PubMed]

62. Gleich, A.; Kaiser, B.; Schumann, J.; Fuhrmann, H. Establishment and Characterisation of a Novel Bovine SV40 Large T-AntigenTransduced Foetal Hepatocyte-Derived Cell Line. In Vitro Cell. Dev. Biol. 2016, 52, 662-672. [CrossRef] [PubMed]

63. Pauletto, M.; Tolosi, R.; Giantin, M.; Guerra, G.; Barbarossa, A.; Zaghini, A.; Dacasto, M. Insights into Aflatoxin B1 Toxicity in Cattle: An In Vitro Whole-Transcriptomic Approach. Toxins 2020, 12, 429. [CrossRef] [PubMed]

64. Robinson, M.D.; McCarthy, D.J.; Smyth, G.K. EdgeR: A Bioconductor Package for Differential Expression Analysis of Digital Gene Expression Data. Bioinformatics 2010, 26, 139-140. [CrossRef] [PubMed]

65. Yu, G.; Wang, L.G.; Han, Y.; He, Q.Y. ClusterProfiler: An R Package for Comparing Biological Themes among Gene Clusters. OMICS J. Integrat. Biol. 2012, 16, 284-287. [CrossRef]

66. Subramanian, A.; Tamayo, P.; Mootha, V.K.; Mukherjee, S.; Ebert, B.L.; Gillette, M.A.; Paulovich, A.; Pomeroy, S.L.; Golub, T.R.; Lander, E.S.; et al. Gene Set Enrichment Analysis: A Knowledge-Based Approach for Interpreting Genome-Wide Expression Profiles. Proc. Natl. Acad. Sci. USA 2005, 102, 15545-15550. [CrossRef]

67. Ross, D.; Siegel, D. Functions of NQO1 in Cellular Protection and CoQ10 Metabolism and Its Potential Role as a Redox Sensitive Molecular Switch. Front. Physiol. 2017, 8, 595. [CrossRef] [PubMed]

68. Zancanella, V.; Giantin, M.; Dacasto, M. Absolute Quantification and Modulation of Cytochrome P450 3A Isoforms in Cattle Liver. Vet. J. 2014. [CrossRef]

69. Joe, A.K.; Liu, H.; Suzui, M.; Vural, M.E.; Xiao, D.; Weinstein, I.B. Resveratrol Induces Growth Inhibition, S-Phase Arrest, Apoptosis, and Changes in Biomarker Expression in Several Human Cancer Cell Lines. Clin. Cancer Res. 2002, 8, 893-903. [PubMed]

70. Wu, H.; Chen, L.; Zhu, F.; Han, X.; Sun, L.; Chen, K. The Cytotoxicity Effect of Resveratrol: Cell Cycle Arrest and Induced Apoptosis of Breast Cancer 4T1 Cells. Toxins 2019, 11, 731. [CrossRef]

71. El Khoury, A.; Atoui, A.; Yaghi, J. Analysis of Aflatoxin M1 in Milk and Yogurt and AFM1 Reduction by Lactic Acid Bacteria Used in Lebanese Industry. Food Control 2011, 22, 1695-1699. [CrossRef]

72. Kuilman, M.E.M.; Maas, R.F.M.; Fink-Gremmels, J. Cytochrome P450-Mediated Metabolism and Cytotoxicity of Aflatoxin B1 in Bovine Hepatocytes. Toxicology Vitr. 2000, 14, 321-327. [CrossRef]

73. Min, L.; Fink-Gremmels, J.; Li, D.; Tong, X.; Tang, J.; Nan, X.; Yu, Z.; Chen, W.; Wang, G. An Overview of Aflatoxin B1 Biotransformation and Aflatoxin M1 Secretion in Lactating Dairy Cows. Anim. Nutr. 2021, 7, 42-48. [CrossRef] 
74. Nakazato, M.; Morozumi, S.; Saito, K.; Fujinuma, K.; Nishima, T.; Kasai, N. Interconversion of Aflatoxin B1 and Aflatoxicol by Several Fungi. Appl. Environ. Microbiol. 1990, 56, 1465-1470. [CrossRef] [PubMed]

75. Murcia, H.W.; Diaz, G.J. In Vitro Hepatic Aflatoxicol Production Is Related to a Higher Resistance to Aflatoxin B1 in Poultry. Sci. Rep. 2020, 10, 5508. [CrossRef]

76. Kühn, G.; Pallauf, K.; Schulz, C.; Birringer, M.; Diaz-Rica, B.; de Pascual-Teresa, S.; Rimbach, G. Resveratrol Modulates Desaturase Expression and Fatty Acid Composition of Cultured Hepatocytes. Front. Nutr. 2018, 5, 106. [CrossRef]

77. Tang, L.; Li, J.; Fu, W.; Wu, W.; Xu, J. Suppression of FADS1 Induces ROS Generation, Cell Cycle Arrest, and Apoptosis in Melanocytes: Implications for Vitiligo. Aging 2019, 11, 11829-11843. [CrossRef]

78. Inoue, H.; Jiang, X.-F.; Katayama, T.; Osada, S.; Umesono, K.; Namura, S. Brain Protection by Resveratrol and Fenofibrate against Stroke Requires Peroxisome Proliferator-Activated Receptor $\alpha$ in Mice. Neurosci. Lett. 2003, 352, 203-206. [CrossRef]

79. Resar, L.M.S. The High Mobility Group A1 Gene: Transforming Inflammatory Signals into Cancer? Cancer Res. 2010, 70, 436-439. [CrossRef]

80. Lund, S.A.; Giachelli, C.M.; Scatena, M. The Role of Osteopontin in Inflammatory Processes. J. Cell Commun. Signal. 2009, 3, 311-322. [CrossRef]

81. Wang, K.X.; Denhardt, D.T. Osteopontin: Role in Immune Regulation and Stress Responses. Cytokine Growth Factor Rev. 2008, 19, 333-345. [CrossRef] [PubMed]

82. Fusco, A.; Fedele, M. Roles of HMGA Proteins in Cancer. Nat. Rev. Cancer 2007, 7, 899-910. [CrossRef] [PubMed]

83. Lin, S.-Y.; Peng, F. Association of SIRT1 and HMGA1 Expression in Non-Small Cell Lung Cancer. Oncol. Lett. 2016, 11, 782-788. [CrossRef] [PubMed]

84. Jin, H.; Lian, N.; Zhang, F.; Chen, L.; Chen, Q.; Lu, C.; Bian, M.; Shao, J.; Wu, L.; Zheng, S. Activation of PPAR $/$ P53 Signaling Is Required for Curcumin to Induce Hepatic Stellate Cell Senescence. Cell Death Dis. 2016, 7, e2189. [CrossRef] [PubMed]

85. Casarin, R.C.; Casati, M.Z.; Pimentel, S.P.; Cirano, F.R.; Algayer, M.; Pires, P.R.; Ghiraldini, B.; Duarte, P.M.; Ribeiro, F.V. Resveratrol Improves Bone Repair by Modulation of Bone Morphogenetic Proteins and Osteopontin Gene Expression in Rats. Int. J. Oral Maxillofac. Surg. 2014, 43, 900-906. [CrossRef]

86. Ozcan-Kucuk, A.; Alan, H.; Gul, M.; Yolcu, U. Evaluating the Effect of Resveratrol on the Healing of Extraction Sockets in Cyclosporine A-Treated Rats. J. Oral Maxillofac. Surg. 2018, 76, 1404-1413. [CrossRef]

87. Tu, C.; Su, Y.; Huang, Y.; Tsai, M.; Li, L.; Chen, Y.; Cheng, C.; Dai, D.; Yang, R. Localization and Characterization of a Novel Secreted Protein SCUBE1 in Human Platelets. Cardiovasc. Res. 2006, 71, 486-495. [CrossRef]

88. Erdoğan, M.; Findikli, H.A.; Okuducu Teran, İ. A Novel Biomarker for Predicting Sepsis Mortality: SCUBE-1. Medicine 2021, 100, e24671. [CrossRef]

89. Knaus, W.A.; Draper, E.A.; Wagner, D.P.; Zimmerman, J.E. APACHE II: A Severity of Disease Classification System. Crit. Care Med. 1985, 13, 818-829. [CrossRef] [PubMed]

90. Dai, D.-F.; Thajeb, P.; Tu, C.-F.; Chiang, F.-T.; Chen, C.-H.; Yang, R.-B.; Chen, J.-J. Plasma Concentration of SCUBE1, a Novel Platelet Protein, Is Elevated in Patients With Acute Coronary Syndrome and Ischemic Stroke. J. Am. Coll. Cardiol. 2008, 51, 2173-2180. [CrossRef] [PubMed]

91. Erol, O.; Ellidağ, H.Y.; Özel, M.K.; Uysal Derbent, A.; Eren, E.; Yılmaz, N. Circulating SCUBE1 Levels in Women with Polycystic Ovary Syndrome. J. Turk. Soc. Obstet. Gynecol. 2018, 15, 152-158. [CrossRef] [PubMed]

92. Uyanikoglu, H.; Hilali, N.G.; Yardimciel, M.; Koyuncu, I. A New Biomarker for the Early Diagnosis of Ovarian Torsion: SCUBE-1. Clin. Exp. Reprod. Med. 2018, 45, 94-99. [CrossRef] [PubMed]

93. Gordon, S.M.; Hofmann, S.; Askew, D.S.; Davidson, W.S. High Density Lipoprotein: It's Not Just about Lipid Transport Anymore. Trends Endocrinol. Metab. 2011, 22, 9-15. [CrossRef] [PubMed]

94. Georgila, K.; Vyrla, D.; Drakos, E. Apolipoprotein A-I (ApoA-I), Immunity, Inflammation and Cancer. Cancers 2019, $11,1097$. [CrossRef] [PubMed]

95. Keith, R.L.; Miller, Y.E.; Hudish, T.M.; Girod, C.E.; Sotto-Santiago, S.; Franklin, W.A.; Nemenoff, R.A.; March, T.H.; Nana-Sinkam, S.P.; Geraci, M.W. Pulmonary Prostacyclin Synthase Overexpression Chemoprevents Tobacco Smoke Lung Carcinogenesis in Mice. Cancer Res. 2004, 64, 5897-5904. [CrossRef] [PubMed]

96. Pan, X.; Yang, Y.; Meng, H.; Li, H.; Chen, X.; Huang, H.; Bu, F.; Yu, H.; Wang, Q.; Huang, C.; et al. DNA Methylation of PTGIS Enhances Hepatic Stellate Cells Activation and Liver Fibrogenesis. Front. Pharmacol. 2018, 9, 553. [CrossRef] [PubMed]

97. Pal, S.; Ho, N.; Santos, C.; Dubois, P.; Mamo, J.; Croft, K.; Allister, E. Red Wine Polyphenolics Increase LDL Receptor Expression and Activity and Suppress the Secretion of ApoB100 from Human HepG2 Cells. J. Nutr. 2003, 133, 700-706. [CrossRef]

98. Yashiro, T.; Nanmoku, M.; Shimizu, M.; Inoue, J.; Sato, R. Resveratrol Increases the Expression and Activity of the Low Density Lipoprotein Receptor in Hepatocytes by the Proteolytic Activation of the Sterol Regulatory Element-Binding Proteins. Atherosclerosis 2012, 220, 369-374. [CrossRef] [PubMed]

99. Lee, I.-T.; Lin, C.-F.; Huang, Y.-L.; Chong, K.-Y.; Hsieh, M.-F.; Huang, T.-H.; Cheng, C.-Y. Protective Mechanisms of Resveratrol Derivatives against TNF- $\alpha$-Induced Inflammatory Responses in Rat Mesangial Cells. Cytokine 2019, 113, 380-392. [CrossRef]

100. Bellezza, I.; Roberti, R.; Gatticchi, L.; Del Sordo, R.; Rambotti, M.G.; Marchetti, M.C.; Sidoni, A.; Minelli, A. A Novel Role for Tm7sf2 Gene in Regulating TNF $\alpha$ Expression. PLoS ONE 2013, 8, e68017. [CrossRef]

101. Gatticchi, L.; Bellezza, I.; Del Sordo, R.; Peirce, M.J.; Sidoni, A.; Roberti, R.; Minelli, A. The Tm7sf2 Gene Deficiency Protects Mice against Endotoxin-Induced Acute Kidney Injury. PLoS ONE 2015, 10, e0141885. [CrossRef] 
102. Li, B.; Liu, C.; Tang, K.; Dong, X.; Xue, L.; Su, G.; Zhang, W.; Jin, Y. Aquaporin-1 Attenuates Macrophage-Mediated Inflammatory Responses by Inhibiting P38 Mitogen-Activated Protein Kinase Activation in Lipopolysaccharide-Induced Acute Kidney Injury. Inflamm. Res. 2019, 68, 1035-1047. [CrossRef]

103. Wang, Y.; Zhang, W.; Yu, G.; Liu, Q.; Jin, Y. Cytoprotective Effect of Aquaporin 1 against Lipopolysaccharide-induced Apoptosis and Inflammation of Renal Epithelial HK-2 Cells. Exp. Ther. Med. 2018. [CrossRef]

104. Ray, N.; Kuwahara, M.; Takada, Y.; Maruyama, K.; Kawaguchi, T.; Tsubone, H.; Ishikawa, H.; Matsuo, K. C-Fos Suppresses Systemic Inflammatory Response to Endotoxin. Int. Immunol. 2006, 18, 671-677. [CrossRef]

105. Thiel, G.; Rössler, O.G. Resveratrol Stimulates C-Fos Gene Transcription via Activation of ERK1/2 Involving Multiple Genetic Elements. Gene 2018, 658, 70-75. [CrossRef] [PubMed]

106. Modica, S.; Gadaleta, R.M.; Moschetta, A. Deciphering the Nuclear Bile Acid Receptor FXR Paradigm. Nucl. Recept. Signal. 2010, 8. [CrossRef]

107. Bergamaschini, L.; Gobbo, G.; Gatti, S.; Caccamo, L.; Prato, P.; Maggioni, M.; Braidotti, P.; Di Stefano, R.; Fassati, L.R. Endothelial Targeting with C1-Inhibitor Reduces Complement Activation in vitro and during ex vivo Reperfusion of Pig Liver: Reduction of Ischaemia-Reperfusion Injury by Cell-Bound C1-INH. Clin. Exp. Immunol. 2001, 126, 412-420. [CrossRef]

108. Bosma, M.; Gerling, M.; Pasto, J.; Georgiadi, A.; Graham, E.; Shilkova, O.; Iwata, Y.; Almer, S.; Söderman, J.; Toftgård, R.; et al. FNDC4 Acts as an Anti-Inflammatory Factor on Macrophages and Improves Colitis in Mice. Nat. Commun. 2016, 7, 11314. [CrossRef]

109. Koniaris, L.G.; Zimmers-Koniaris, T.; Hsiao, E.C.; Chavin, K.; Sitzmann, J.V.; Farber, J.M. Cytokine-Responsive Gene-2/IFNInducible Protein-10 Expression in Multiple Models of Liver and Bile Duct Injury Suggests a Role in Tissue Regeneration. J. Immunol. 2001, 167, 399-406. [CrossRef]

110. Bone-Larson, C.L.; Hogaboam, C.M.; Evanhoff, H.; Strieter, R.M.; Kunkel, S.L. IFN- $\gamma$-Inducible Protein-10 (CXCL10) Is Hepatoprotective During Acute Liver Injury Through the Induction of CXCR2 on Hepatocytes. J. Immunol. 2001, 167, 7077-7083. [CrossRef] [PubMed]

111. Tu, C.; Han, B.; Liu, H.; Zhang, S. Curcumin Protects Mice against Concanavalin A-Induced Hepatitis by Inhibiting Intrahepatic Intercellular Adhesion Molecule-1 (ICAM-1) and CXCL10 Expression. Mol. Cell. Biochem. 2011, 358, 53-60. [CrossRef]

112. Kutty, R.K.; Samuel, W.; Abay, R.; Cherukuri, A.; Nagineni, C.N.; Duncan, T.; Jaworski, C.; Vijayasarathy, C.; Redmond, T.M. Resveratrol Attenuates CXCL11 Expression Induced by Proinflammatory Cytokines in Retinal Pigment Epithelial Cells. Cytokine 2015, 74, 335-338. [CrossRef]

113. Zeremski, M.; Petrovic, L.M.; Chiriboga, L.; Brown, Q.B.; Yee, H.T.; Kinkhabwala, M.; Jacobson, I.M.; Dimova, R.; Markatou, M.; Talal, A.H. Intrahepatic Levels of CXCR3-Associated Chemokines Correlate with Liver Inflammation and Fibrosis in Chronic Hepatitis C. Hepatology 2008, 48, 1440-1450. [CrossRef]

114. Simpson, K.J.; Henderson, N.C.; Bone-Larson, C.L.; Lukacs, N.W.; Hogaboam, C.M.; Kunkel, S.L. Chemokines in the Pathogenesis of Liver Disease: So Many Players with Poorly Defined Roles. Clin. Sci. 2003, 104, 47-63. [CrossRef]

115. Azhar, N.; Ziraldo, C.; Barclay, D.; Rudnick, D.A.; Squires, R.H.; Vodovotz, Y. Analysis of Serum Inflammatory Mediators Identifies Unique Dynamic Networks Associated with Death and Spontaneous Survival in Pediatric Acute Liver Failure. PLoS ONE 2013, 8, e78202. [CrossRef] [PubMed]

116. Yu, W.; Wang, J.; Ma, L.; Tang, X.; Qiao, Y.; Pan, Q.; Yu, Y.; Sun, F. CD166 Plays a Pro-Carcinogenic Role in Liver Cancer Cells via Inhibition of FOXO Proteins through AKT. Oncol. Rep. 2014, 32, 677-683. [CrossRef]

117. Zendehdel, E.; Abdollahi, E.; Momtazi-Borojeni, A.A.; Korani, M.; Alavizadeh, S.H.; Sahebkar, A. The Molecular Mechanisms of Curcumin's Inhibitory Effects on Cancer Stem Cells. J. Cell. Biochem. 2019, 120, 4739-4747. [CrossRef]

118. Li, M.; Xu, D.; Xia, X.; Ni, B.; Zhu, C.; Zhao, G.; Cao, H. Sema3C Promotes Hepatic Metastasis and Predicts Poor Prognosis in Gastric Adenocarcinoma. J. Int. Med. Res. 2021, 49. [CrossRef]

119. Papic, N.; Zidovec Lepej, S.; Gorenec, L.; Grgic, I.; Gasparov, S.; Filipec Kanizaj, T.; Vince, A. The Association of Semaphorins 3C, 5A and 6D with Liver Fibrosis Stage in Chronic Hepatitis C. PLoS ONE 2018, 13, e0209481. [CrossRef]

120. Gilkerson, R.; De La Torre, P.; Vallier, S.S. Mitochondrial OMA1 and OPA1 as Gatekeepers of Organellar Structure/Function and Cellular Stress Response. Front. Cell Dev. Biol. 2021, 9, 626117. [CrossRef]

121. Garcia, I.; Innis-Whitehouse, W.; Lopez, A.; Keniry, M.; Gilkerson, R. Oxidative Insults Disrupt OPA1-Mediated Mitochondrial Dynamics in Cultured Mammalian Cells. Redox Rep. 2018, 23, 160-167. [CrossRef]

122. Pang, Y.; Qin, M.; Hu, P.; Ji, K.; Xiao, R.; Sun, N.; Pan, X.; Zhang, X. Resveratrol Protects Retinal Ganglion Cells against Ischemia Induced Damage by Increasing Opa1 Expression. Int. J. Mol. Med. 2020. [CrossRef] [PubMed]

123. Chan, W.K.; Delucchi, A.B. Resveratrol, a Red Wine Constituent, Is a Mechanism-Based Inactivator of Cytochrome P450 3A4. Life Sci. 2000, 67, 3103-3112. [CrossRef]

124. Boshuizen, M.; van der Ploeg, K.; von Bonsdorff, L.; Biemond, B.J.; Zeerleder, S.S.; van Bruggen, R.; Juffermans, N.P. Therapeutic Use of Transferrin to Modulate Anemia and Conditions of Iron Toxicity. Blood Rev. 2017, 31, 400-405. [CrossRef]

125. Chen, Y.-I.; Wei, P.-C.; Hsu, J.-L.; Su, F.-Y.; Lee, W.-H. NPGPx (GPx7): A Novel Oxidative Stress Sensor/Transmitter with Multiple Roles in Redox Homeostasis. Am. J. Transl. Res. 2016, 8, 1626-1640.

126. Hanmer, K.L.; Mavri-Damelin, D. Peroxidasin Is a Novel Target of the Redox-Sensitive Transcription Factor Nrf2. Gene 2018, 674, 104-114. [CrossRef] 
127. Dougan, J.; Hawsawi, O.; Burton, L.J.; Edwards, G.; Jones, K.; Zou, J.; Nagappan, P.; Wang, G.; Zhang, Q.; Danaher, A.; et al. Proteomics-Metabolomics Combined Approach Identifies Peroxidasin as a Protector against Metabolic and Oxidative Stress in Prostate Cancer. Int. J. Mol. Sci. 2019, 20, 3046. [CrossRef] [PubMed]

128. Mathieu, L.; Lopes Costa, A.; Le Bachelier, C.; Slama, A.; Lebre, A.-S.; Taylor, R.W.; Bastin, J.; Djouadi, F. Resveratrol Attenuates Oxidative Stress in Mitochondrial Complex I Deficiency: Involvement of SIRT3. Free Radic. Biol. Med. 2016, 96, 190-198. [CrossRef] [PubMed]

129. Fu, B.; Zhao, J.; Peng, W.; Wu, H.; Zhang, Y. Resveratrol Rescues Cadmium-Induced Mitochondrial Injury by Enhancing Transcriptional Regulation of PGC-1 $\alpha$ and SOD2 via the Sirt3/FoxO3a Pathway in TCMK-1 Cells. Biochem. Biophys. Res. Commun. 2017, 486, 198-204. [CrossRef] [PubMed]

130. Zhou, X.; Chen, M.; Zeng, X.; Yang, J.; Deng, H.; Yi, L.; Mi, M. Resveratrol Regulates Mitochondrial Reactive Oxygen Species Homeostasis through Sirt3 Signaling Pathway in Human Vascular Endothelial Cells. Cell Death Dis. 2014, 5, e1576. [CrossRef]

131. Morgenstern, R.; Zhang, J.; Johansson, K. Microsomal Glutathione Transferase 1: Mechanism and Functional Roles. Drug Metabol. Rev. 2011, 43, 300-306. [CrossRef] [PubMed]

132. Meng, Q.; Guo, T.; Li, G.; Sun, S.; He, S.; Cheng, B.; Shi, B.; Shan, A. Dietary Resveratrol Improves Antioxidant Status of Sows and Piglets and Regulates Antioxidant Gene Expression in Placenta by Keap1-Nrf2 Pathway and Sirt1. J. Anim. Sci. Biotechnol. 2018, 9, 34. [CrossRef]

133. Chanas, S.A.; Jiang, Q.; McMahon, M.; McWalter, G.K.; McLellan, L.I.; Elcombe, C.R.; Henderson, C.J.; Wolf, C.R.; Moffat, G.J.; Itoh, K.; et al. Loss of the Nrf2 Transcription Factor Causes a Marked Reduction in Constitutive and Inducible Expression of the Glutathione S-Transferase Gsta1, Gsta2, Gstm1, Gstm2, Gstm3 and Gstm4 Genes in the Livers of Male and Female Mice. Biochem. J. 2002, 365, 405-416. [CrossRef] [PubMed]

134. Chang, J.; Ma, J.Z.; Zeng, Q.; Cechova, S.; Gantz, A.; Nievergelt, C.; O'Connor, D.; Lipkowitz, M.; Le, T.H. Loss of GSTM1, a NRF2 Target, Is Associated with Accelerated Progression of Hypertensive Kidney Disease in the African American Study of Kidney Disease (AASK). Am. J. Physiol. Renal Physiol. 2013, 304, F348-F355. [CrossRef] [PubMed]

135. Dodson, M.; Anandhan, A.; Zhang, D.D. MGST1, a New Soldier of NRF2 in the Battle against Ferroptotic Death. Cell Chem. Biol. 2021, 28, 741-742. [CrossRef] [PubMed]

136. Voloshyna, I.; Hai, O.; Littlefield, M.J.; Carsons, S.; Reiss, A.B. Resveratrol Mediates Anti-Atherogenic Effects on Cholesterol Flux in Human Macrophages and Endothelium via PPAR $\gamma$ and Adenosine. Eur. J. Pharmacol. 2013, 698, 299-309. [CrossRef]

137. Wang, Z.; Zhang, L.; Ni, Z.; Sun, J.; Gao, H.; Cheng, Z.; Xu, J.; Yin, P. Resveratrol Induces AMPK-Dependent MDR1 Inhibition in Colorectal Cancer HCT116/L-OHP Cells by Preventing Activation of NF-KB Signaling and Suppressing CAMP-Responsive Element Transcriptional Activity. Tumor Biol. 2015, 36, 9499-9510. [CrossRef] [PubMed]

138. Lorico, A.; Nesland, J.; Emilsen, E.; Fodstad, O.; Rappa, G. Role of the Multidrug Resistance Protein 1 Gene in the Carcinogenicity of Aflatoxin B1: Investigations Using Mrp1-Null Mice. Toxicology 2002, 171, 201-205. [CrossRef]

139. Van Herwaarden, A.E.; Wagenaar, E.; Karnekamp, B.; Merino, G.; Jonker, J.W.; Schinkel, A.H. Breast Cancer Resistance Protein (Bcrp1/Abcg2) Reduces Systemic Exposure of the Dietary Carcinogens Aflatoxin B1, IQ and Trp-P-1 but Also Mediates Their Secretion into Breast Milk. Carcinogenesis 2005, 27, 123-130. [CrossRef]

140. Zhang, Y.; Na, Z.; Chen, D.; Huang, G.; Cao, H. Investigation of the Transport of Aflatoxin M1 by the Transporter ABCG2 in Bovine Mammary Epithelial Cells. Med. Weter. 2020, 76, 646-651. [CrossRef] 